\title{
LA CRISIS VENEZOLANA (2016-2020) A LA LUZ DEL DERECHO INTERNACIONAL PÚBLICO
}

\section{The Venezuelan CRisis (2016-2020) in the light of Public INTERNATIONAL LAW}

\author{
Alejandro Pastori Fillol \\ Sebastián Ramos
}

\begin{abstract}
RESUMEN
En este trabajo se aborda la crisis venezolana (2016-2020) desde la perspectiva del derecho internacional. Para ello, se estudian diversos hitos de particular impacto a nivel internacional, sus consecuencias y el derecho aplicable a cada uno. El ordenamiento democrático de Venezuela, la legalidad del desconocimiento del gobierno de Nicolás Maduro, el reconocimiento internacional del gobierno de Juan Guaidó, las violaciones de derechos humanos por parte de las fuerzas de seguridad venezolanas y las múltiples instancias de presión externa, son las aristas más importantes del análisis, en donde gravita fundamentalmente este estudio. Se concluye, entre otras, que el gobierno actual de Venezuela no es un régimen democrático, que el reconocimiento de Juan Guaidó no es jurídicamente sostenible, que el Estado venezolano es responsable por las sistemáticas violaciones de derechos humanos cometidas por sus cuerpos de seguridad en contra de la población civil y que las medidas de coerción unilateral, fundamentalmente el embargo económico ejercido por Estados Unidos, contravienen normas internacionales incluidas en la Carta de las Naciones Unidas.
\end{abstract}

\section{PALABRAS CLAVE}

Crisis en Venezuela; Venezuela; Derecho Internacional; Derechos Humanos; Responsabilidad del Estado

\begin{abstract}
This work deals with the Venezuelan crisis (2016-2020) from the perspective of international law. For this, various milestones of particular impact at the international level, their consequences, and the applicable law to each one are studied. The democratic order of Venezuela, the legality of the recognition withdraw of the government of Nicolás Maduro, the international recognition of the government of Juan Guaidó, the human rights violations by the Venezuelan security forces, and the multiple instances of external pressure are the most important topics of analysis, where this study fundamentally gravitates. It is concluded, among others, that the current government of Venezuela does not configure a democratic system, that the recognition of Juan Guaidó is not legally sustainable, that the Venezuelan State is responsible for the systematic human rights violations committed by its security forces against of the civilian population, and that unilateral coercion measures, fundamentally the economic embargo exercised by the United States, contravenes international rules included in the United Nations Charter.
\end{abstract}

\section{KEY WORDS}

Venezuelan Crisis; Venezuela; International Law; Human Rights; State Responsibility. 


\section{INTRODUCCIÓN}

Desde el fallecimiento de Hugo Chávez en 2013 y la consecuente llegada al poder de Nicolás Maduro en el mismo año, la crisis social, económica e institucional en Venezuela ha dado lugar a una serie de hitos que revisten particular interés en ser analizados a la luz del derecho internacional. Estos eventos a los que hacemos mención han sido abordados por diversos actores institucionales, políticos y medios de prensa y se le han dedicado también algunos estudios académicos a cada uno de ellos individualmente.

Este trabajo en cambio tiene la particularidad de seleccionar aquellos eventos más importantes y controversiales de los últimos años y de reunirlos a todos en un único trabajo de análisis jurídico que permita una visión general, encadenada y cronológica de lo ocurrido, siempre evaluando los hechos desde la perspectiva del derecho internacional.

Por cierto, a cada uno de estos sucesos se le podría dedicar un espacio propio y exclusivo, especialmente a los que tienen multiplicidad de dimensiones alcanzadas por la disciplina jurídica, no obstante, como ese no es el objetivo de este trabajo, se buscará un abordaje concreto y lo más preciso posible para poder obtener la necesaria visión de conjunto de toda la compleja situación venezolana.

Tomaremos como punto de partida para nuestro análisis, el momento más álgido de tensión institucional durante la primera presidencia de Nicolás Maduro: el enfrentamiento entre el Tribunal Supremo de Justicia y la Asamblea Nacional que se inició en 2016, hasta llegar al 21 de setiembre de 2020, fecha de entrega de este artículo.

Este trabajo se divide en cinco partes, con la intención de aglutinar temática y cronológicamente los sucesos a analizar. Las primeras dos partes (puntos 2 y 3 ) corresponden a la crisis institucional de Venezuela entre 2016 y 2020. La tercera parte (punto 4) refiere, exclusivamente, a los mecanismos internacionales tendientes a darle solución. La siguiente parte (punto 5) analiza las violaciones de derechos humanos ocurridas dentro del país, durante este período, haciendo especial hincapié en los informes de los Altos Comisionados de Naciones Unidas para los Derechos Humanos. La última parte (punto 6) aborda los impactos directos de otros Estados en la crisis venezolana, su influencia e injerencia. En el punto 7 se incluirán las conclusiones de 
este trabajo, donde se exponen los principales resultados del análisis jurídico de cada tema.

\section{Primera CRISIS INSTITUCIONAL}

En enero de 2016 el Tribunal Supremo de Justicia de Venezuela (TSJ) declaró "en desacato" a la Asamblea Nacional (AN) venezolana (Sentencia No01, 2016; DW Español, 2016), luego de que esta no cumpliera con una serie de sentencias que establecían la "suspensión" de cuatro diputados (Sentencia N²60, 2015). El origen de la situación se encontraba en las elecciones parlamentarias del año anterior y las denuncias judiciales sobre fraude electoral llevadas adelante por el oficialismo. El estado de desacato traía graves consecuencias consigo: la declaración de nulidad de todos los actos de la asamblea parlamentaria mientras esta no cumpliera con la "desincoporación" de los diputados suspendidos.

La situación de bloqueo institucional continuó durante todo el 2016 y parte del 2017. El parlamento venezolano sancionó durante este período varias leyes -entre las más relevantes la Ley de Amnistía (2016) ${ }^{1}$ - que se encontraron con la oposición directa del TSJ y del Ejecutivo (Europa Press, 2016). La ostensible confrontación política entre estos órganos supuso una paralización institucional total.

Esta suerte de statu quo desarrollado durante este período entre oposición y oficialismo comenzó a fracturarse durante la primera mitad de 2017. El 28 de marzo se publicó la sentencia $N^{\circ} 155$ de la Sala Constitucional del TSJ, un dictamen que puso en cuestión, principalmente, la inmunidad parlamentaria de los diputados de la AN y que otorgó poderes especiales al presidente Nicolás Maduro. La sentencia subsiguiente, №156 del 29 de marzo, da un paso más dado que mandata que:

Mientras persista la situación de desacato y de invalidez de las actuaciones de la Asamblea Nacional, esta Sala Constitucional garantizará que las competencias parlamentarias sean ejercidas directamente por esta Sala o por el órgano que ella disponga, para velar por el Estado de Derecho (Sentencia №156, 2017, punto 4.4).

De esta forma el TSJ absorbió para sí las funciones del parlamento.

\footnotetext{
${ }^{1}$ Esta ley fue declarada inconstitucional por el TSJ mediante sentencia del 11 de abril de 2016.
} 
La inmediata y abrumadora respuesta nacional (BBC Mundo, 2017a; El Español, 2017) e internacional a estos dictámenes presionaron al TSJ que, tras una recomendación del poder ejecutivo venezolano (Univisión, 2017), suprimió las líneas más controversiales de estos fallos ${ }^{2}$. No obstante este retroceso, la crisis se había desatado. El malestar popular se manifestó en las calles, hubo protestas pidiendo la renuncia de los magistrados así como el llamado a elecciones anticipadas, y se denunciaron incontables actos de violencia y de represión contra los manifestantes ${ }^{3}$.

El 1 de mayo de 2017 el presidente Nicolás Maduro, mediante el decreto presidencial №2830, convocó una Asamblea Nacional Constituyente (ANC). Esto configuró un nuevo y polémico capítulo en la crisis institucional venezolana a pocos días de las sentencias del TSJ.

En lo discursivo, el objetivo del proceso constituyente era:

Una gran convocatoria a un diálogo nacional para contener la escalada de violencia política, mediante el reconocimiento político mutuo y de una reorganización del Estado, que recupere el principio constitucional de cooperación entre los poderes públicos, como garantía del pleno funcionamiento del Estado democrático... (Decreto №2830, 2017, p. 2).

Parecía ser esta una respuesta, por parte del gobierno, a la necesidad del restablecimiento de la institucionalidad democrática.

No obstante, la realidad fue muy distinta a los cometidos enarbolados por el documento. Más allá de los cuestionamientos sobre la legalidad de convocar a una Asamblea Constituyente por decreto del ejecutivo (Sánchez, 2019, pp. 9-30; Colina y Vanolli, 2017; DW Español, 2017), el organismo no fue aceptado como mecanismo legítimo por la oposición, quedando prácticamente en su totalidad por fuera de una asamblea que, por lógica electoral, debía mantener, al menos significativamente, una proporción de representatividad comparable con la del parlamento nacional cuyas elecciones habían ocurrido un año y medio atrás. La abstención general de la oposición y sectores críticos con el gobierno -que se sitúa entre el $58 \%$ de votantes en las cifras oficiales (BBC Mundo, 2017b) y el $87 \%$ en las estimaciones opositoras

\footnotetext{
${ }^{2}$ Véase la Sentencia №157 (2017) decisión que suprimió parte del dictamen №155, y la Sentencia $\mathrm{N}^{\circ} 158$ (2017) que suprimió parte del dictamen №156.

${ }^{3}$ El punto 5 de este trabajo aborda específicamente estas situaciones.
} 
(Infobae, 2017)- resultó en la composición total de la Asamblea Constituyente con candidatos oficialistas o políticamente alineados con el gobierno (Colina y Vanolli, 2017), tras el proceso electoral del 30 de julio.

El 4 de agosto de 2017 la ANC sesionó por primera vez (BBC Mundo, 2017c). No hubo que esperar demasiado antes de que comenzara a dictaminar controversiales normativas que, al igual que las sentencias del TSJ, recibirían el rechazo tanto de sectores nacionales como extranjeros. Dos decretos cobran especial relevancia para este análisis, tanto desde una perspectiva jurídica como desde una perspectiva cronológica. El primero ocurre a dos semanas del inicio de sesiones de la ANC. EI 18 de agosto de 2017 la Constituyente decretó de forma unánime la asunción de las competencias legislativas parlamentarias (BBC Mundo, 2017d), efectivizando lo que el TSJ tuvo que suprimir mediante su sentencia $N^{\circ} 158$. El segundo decreto del 23 de enero de 2018, adelantó las elecciones presidenciales en Venezuela para el primer cuatrimestre del año, cuando en la Constitución se establecían los meses de octubre o diciembre al cumplirse los seis años de ciclo gubernamental (Vinogradoff, 2018). La importancia de este acto radica en sus consecuencias, dado que inició el proceso que culminaría en una nueva etapa de crisis institucional en el país: la existencia de dos autoridades presidenciales respaldadas por partidarios locales e internacionales, la cual será abordada en el punto 3 de este trabajo ${ }^{4}$.

La crisis institucional hasta este momento podría resumirse en los siguientes términos. Por un lado el Poder Ejecutivo, el Poder Judicial y la Asamblea Constituyente, tres poderes públicos con abrumadora participación oficialista que sostienen el estado de ilegalidad del parlamento, el cual fue declarado en desacato por el TSJ. Este estado de ilegalidad justificó la toma de ciertas medidas para circunvalar la participación del legislativo en la maquinaria del Estado. Entre estas medidas se encuentran las sentencias -revocadas- del TSJ, la convocación a la ANC y su posterior decreto de asunción de competencias parlamentarias.

\footnotetext{
${ }^{4}$ Otros decretos subrayables de la ANC durante este período fueron la destitución de la Fiscal General Luisa Ortega Díaz (5 de agosto de 2017), el levantamiento de la inmunidad parlamentaria de los diputados de la Asamblea Nacional Germán Ferrer (6 de agosto de 2017), Freddy Guevara (6 de noviembre de 2017), Juan Requesens y Julio Borges (8 de agosto de 2017), adelanto de las elecciones regionales y subordinación de los gobernadores electos a su autoridad como requisito para su investidura (18 de octubre de 2017) y aprobación de la Ley contra el Odio (8 de noviembre de 2017), criticada por su agresivo avance sobre las libertades individuales.
} 
Por otro, tenemos la posición de la Asamblea Nacional venezolana, la cual define como ilegales las sentencias del TSJ que proscribieron a cuatro de sus miembros democráticamente electos, señalando que ellas son una maniobra política con el objetivo de coartar la mayoría absoluta de la oposición en el parlamento. Asimismo, estiman inconstitucional la convocatoria a la ANC así como inválidos cualesquiera de sus actos. Las normas emanadas desde estos poderes, cuyos objetivos son amedrentar a los legisladores electos o menoscabar la capacidad del parlamento, son tachados de actos de persecución política en un contexto de tensión y conflicto entre representantes legítimos y un régimen de facto.

Análisis jurídico de estos hechos desde la perspectiva del Derecho Internacional Público:

\section{1. El derecho de la Organización de Estados Americanos y su aplicación al caso}

Si bien el derecho internacional general no se inmiscuye en las disposiciones internas de los Estados -dado que esto compete sólo a estos- ni a la organización política de gobierno que soberanamente adoptan, sí existen normas aplicables al caso concreto. En principio, en el plano multilateral, la no existencia de un régimen democrático no puede ser objeto de una sanción por el derecho internacional general por ese solo hecho (Pastori, 2020, pp. 32-33), salvo en el caso que describimos a continuación. Nos referimos específicamente a los casos en que existan normas acordadas por los Estados miembros sobre la necesidad de tener un gobierno democrático como requisito para la pertenencia a una organización internacional.

En este sentido, los miembros de la Organización de Estados Americanos (OEA) así como los del Mercado Común del Sur (MERCOSUR) se han obligado, mediante el acuerdo de normas mutuamente exigibles ${ }^{5}$, a mantener y preservar una determinada estructura jurídica e institucional interna como requisito sine qua non de su participación en estas organizaciones ${ }^{6}$. Resulta por lo tanto necesario que a la luz de

\footnotetext{
${ }^{5}$ Los instrumentos referidos son la propia Carta de la Organización de Estados Americanos (1948) y la Carta Democrática Interamericana (2001) para la OEA y el Protocolo de Ushuaia sobre Compromiso Democrático (1998) para el MERCOSUR.

${ }^{6}$ El reconocimiento de un gobierno no puede nunca supeditarse a la estructura del Estado, en lo que se denominó como "doctrina legitimista". No obstante, su membresía dentro de una organización internacional puede encontrarse subsumida a esta condición (Crawford, 2012, pp. 151-152; Shaw, 2008, pp. 545-549; Jiménez de Aréchaga et al., 2005, pp. 128-130).
} 
estos instrumentos jurídicos se analice la observancia de lo pactado $\mathrm{y}$, de incumplirse, se proceda a la ejecución de los mecanismos sancionatorios previstos en los mismos.

En este sentido, ¿es la decisión del TSJ de ejercer las competencias parlamentarias, compatible con el derecho internacional? ¿Qué sucede en el caso de la ANC? Para poder responder debemos referirnos a los instrumentos citados previamente.

La Carta de la OEA manifiesta en su preámbulo que la democracia representativa es una "condición indispensable" para la estabilidad de la región. Más adelante, cuando enumera los principios de la organización dispone de forma inequívoca que "(...) los Estados americanos (...) requieren la organización política de los mismos sobre la base del ejercicio efectivo de la democracia representativa" (1948, art.3.d). De esta disposición se extrae el requisito de que los Estados miembros de la OEA sean, necesariamente, democracias representativas. Curiosamente el tratado no brinda ningún tipo de definición adicional sobre el término.

Décadas más tarde, la Carta Democrática Interamericana aportó profundidad a las normas, definió conceptos centrales y vinculó a la democracia representativa con el estado de derecho y los regímenes constitucionales. En su artículo tercero menciona los elementos esenciales que hacen a la democracia representativa, entre otros y fundamentalmente para este estudio, la separación e independencia de los poderes públicos.

Las sentencias $\mathrm{N}^{\circ} 155$ y 156 fueron acciones que, de forma irrefutable e ineludible, configuraron graves violaciones de la separación de los poderes del Estado en una Venezuela que se negaba a calificar sus opacidades institucionales como poco democráticas ${ }^{7}$.

\footnotetext{
${ }^{7}$ Otro evento que evidencia la falta de independencia de los poderes públicos, previo a las sentencias del Tribunal Supremo, fue la designación de 13 magistrados de este órgano y 21 suplentes, el 23 de diciembre de 2015 por una Asamblea Nacional oficialista, la elección se realizó sin contemplar los requisitos constitucionales para tal venia, dado que la norma establece la necesidad de una mayoría especial parlamentaria de dos tercios, mientras que la votación del 23 de diciembre fue de mayoría simple de diputados oficialistas. Cabe anotar que las elecciones parlamentarias habían sido el 6 de diciembre, por lo que ya era de público conocimiento que el próximo legislativo sería de mayoría opositora. Además, investigaciones posteriores revelaron que las trece vacantes que fueron llenadas por este medio se obtuvieron mediante presiones a los magistrados de ese momento, y que los jueces designados tenían afiliación partidaria oficialista o eran ex miembros del gobierno (Salinas y Andreu-Guzmán, 2017, pp. 4-5).
} 
Algunos juristas señalaron que este accionar por parte del TSJ resultaba legal en virtud de la Constitución venezolana, dado que aquel es el custodio del orden jurídico constitucional del país (TeleSUR, 2017). Otros doctrinarios circunscriben esto dentro del concepto de "constitucionalismo abusivo", una idea que supone la progresiva y sutil degradación democrática mediante reformas constitucionales que desbalanceen los poderes públicos y los mecanismos de pesos y contrapesos (Laise y Manzo, 2019; Landau, 2013, pp. 189-260).

En cualquier caso, cada una de las cuatro sentencias mencionadas previamente $\left(N^{\circ} 155,156,157\right.$ o 158) demostró una severa falta de independencia entre los poderes públicos. Ya sea en la sentencia $N^{\circ} 155$, que implicaba el desconocimiento del TSJ de las inmunidades parlamentarias de los diputados nacionales; ya sea en la sentencia $\mathrm{N}^{\circ} 156$, donde la máxima corte de justicia del país se arrogaba capacidad legislativa y potestad de relegar esta capacidad en terceras instituciones; o ya sea en cualesquiera de las sentencias subsiguientes, N157 y 158 , que suprimieron los efectos de las anteriores pero que evidenciaron una clara injerencia del poder ejecutivo ${ }^{8}$.

Es en este sentido que el Consejo Permanente de la OEA se manifestó el 3 de abril de 2017 al decir que estas sentencias eran "incompatibles con la práctica democrática" (OEA, 2017a, punto 1). A partir de ese momento se procedió a la aplicación de los mecanismos definidos en el tratado constitutivo de la organización, en su forma más leve, que suponía exhortar a las autoridades venezolanas a la restitución del orden vigente y el respeto institucional.

La convocatoria posterior de la Asamblea Constituyente, en cambio, encontró a una OEA dividida incapaz de tomar una decisión al respecto. Sólo las palabras de rechazo de su Secretario General Luis Almagro fueron escuchadas a nivel internacional ${ }^{9}$. La organización, como cuerpo, no adoptó ninguna sanción jurídica.

\footnotetext{
${ }^{8}$ Un comunicado emitido por el Consejo de Defensa de la Nación el 1 de abril de 2017, exhortaba al TSJ a revisar sus sentencias $\mathrm{N}^{\circ} 155$ y 156 . La dudosa legalidad de un tribunal reviendo sus propios fallos podría debatirse en otras instancias (BBC Mundo, 2017e).

9 "El proceso realizado ayer es absolutamente nulo, dado que la elección de la Asamblea Constituyente se llevó a cabo masacrando los principios básicos de la transparencia, neutralidad y universalidad que deben caracterizar a comicios libres y confiables." (OEA, 2017b)
} 
El Consejo Permanente volvió a emitir una resolución recién tras el decreto de la ANC cuyo objetivo era adelantar las elecciones presidenciales de 2018. Sin embargo, se reiteraban los términos de la primera resolución. Se exhortaba al gobierno a reconsiderar el calendario electivo, garantizar la independencia de la autoridad electoral y a aceptar la asistencia humanitaria ofrecida por la comunidad internacional $\left(\right.$ OEA, 2018) ${ }^{10}$.

Tendrían que darse las elecciones presidenciales de mayo de 2018, antes de que la OEA diese pasos más firmes con respecto a la aplicación de los instrumentos jurídicos que se dio a sí misma ${ }^{11}$.

\section{2. EI derecho del MERCOSUR y su aplicación al caso}

Las sentencias del TSJ dieron lugar a un análisis similar por parte de los miembros del Mercosur organización de la que Venezuela también es parte. La situación fue considerada como una "ruptura del orden democrático", incompatible con el Protocolo de Ushuaia (1998), en la declaración conjunta del 1 de abril de 2017. En él se instaba al gobierno venezolano a "adoptar inmediatamente medidas concretas (...) para asegurar la efectiva separación de poderes" (MERCOSUR, 2017a, punto 1). Ante el incumplimiento de esta restitución y como respuesta a las turbulentas elecciones de la ANC, el MERCOSUR procedió a aplicar su mecanismo más severo: la suspensión de Venezuela.

El 5 de agosto de 2017 Argentina, Brasil, Paraguay y Uruguay, decidieron aplicar el artículo 6 del Protocolo de Ushuaia suspendiendo a Venezuela en sus derechos y obligaciones inherentes a su condición de Estado parte del MERCOSUR (2017b) ${ }^{12}$. Cabe aclarar que dicha medida resulta ser la más severa entre aquellas aplicables en el marco del instrumento.

Al considerar estas diferencias de posturas entre ambas instituciones, nuestro análisis jurídico respecto de la decisión del MERCOSUR no se centrará en la sanción, sino en el contenido de la norma sobre la que se funda. ¿Cuáles son los criterios adoptados

\footnotetext{
${ }^{10}$ Una resolución sobre la suspensión de Venezuela no pudo ser alcanzada dado que no se logró a tener dos tercios de los votos afirmativos. Esta es una particularidad muy importante del sistema. Véase infra nota 17.

${ }_{11}^{11}$ Ver punto 3 de este trabajo.

12 Resulta evidente que, en comparación con la situación en la que se encontraba la OEA, políticamente paralizada, la decisión del Mercosur se configuró como un acto de categórica definición jurídica (OEA, 2017c)
} 
por las normas del MERCOSUR en materia de democracia? ¿Resultan similares a los establecidos por la OEA? ¿Poseen referencias claras a las cuales recurrir a la hora de una controversia o esta decisión se debe a que el Mercosur tiene un margen más amplio para el debate político que en el organismo regional americano?

El preámbulo del Protocolo de Ushuaia menciona fundamentalmente dos documentos previos: la Declaración Presidencial de Las Leñas del 27 de junio de 1992 y la Declaración Presidencial sobre Compromiso Democrático del 26 de junio de 1996. Ninguno aporta criterios adicionales a los plasmados en el propio tratado, por lo que resulta fútil su estudio.

El artículo primero del Protocolo de Ushuaia determina que "(I)a plena vigencia de las instituciones democráticas es condición esencial" para el proceso de integración entre los Estados parte. Más adelante, en su artículo tercero, el tratado parece vincular esto con el "orden democrático" cuya ruptura habilitará a la aplicación de los mecanismos previstos en el acuerdo. No obstante, al contrario que lo dispuesto taxativamente por la Carta Democrática Interamericana, ni el Protocolo de Ushuaia, ni los documentos en él referenciados, cuentan con una definición jurídica de los conceptos plasmados. Por lo tanto, la conclusión es que efectivamente la ejecución del tratado, supeditado al cumplimiento de criterios no especificados en detalle, tenía un margen de apreciación político mucho más amplio que en el caso de la OEA, más allá de los problemas de las mayorías o consensos propios de cada organización.

Esta carencia se revirtió con la adopción de la Declaración sobre Fortalecimiento de la Democracia en julio de 2019 en cuyas líneas se incluyó una taxonomía sobre los elementos esenciales de la democracia representativa y componentes fundamentales de su ejercicio. Si bien se trata de un apartado prácticamente idéntico al señalado en el instrumento de la OEA, se trata de un paso más firme para conseguir una estabilidad jurídica en materia de democracia y su definición en el Mercosur ${ }^{13}$. Debe resaltarse igualmente que estos criterios fueron adoptados a posteriori de la decisión de suspensión de Venezuela, la que conserva por tanto todas las características de

\footnotetext{
13 "Considerarán que son elementos esenciales de la democracia representativa, entre otros, el respeto de los derechos humanos y las libertades fundamentales; el acceso al poder y su ejercicio con sujeción al estado de derecho; la celebración de elecciones periódicas, libres, justas y basadas en el sufragio universal y secreto como expresión de la soberanía del pueblo; el régimen plural de partidos y organizaciones políticas; y la separación e independencia de los poderes públicos" (MERCOSUR, 2019).
} 
una definición fundamentada en una sola norma jurídica básica (la existencia de una "ruptura del orden democrático"), cuya verificación fue interpretada políticamente.

\section{3. El reconocimiento internacional de la Asamblea Constituyente}

Paralelamente a las acciones jurídicas analizadas de la OEA y el Mercosur la crisis venezolana, especialmente tras la conformación de la ANC, generó una serie de reacciones internacionales susceptibles de ser estudiadas desde la perspectiva del derecho internacional.

De forma especial debe abordarse el reconocimiento y no reconocimiento de la Asamblea Nacional Constituyente por numerosos Estados del mundo. Si bien el instituto de reconocimiento de gobierno forma parte del derecho internacional consuetudinario, tradicionalmente se ha aplicado al Poder Ejecutivo quien es en definitiva el que posee el control territorial efectivo del Estado y quien le representa en su faceta exterior (Lauterpacht, 2013, pp. 87-88). ¿Cuál sería el argumento jurídico para el no reconocimiento de un órgano legislativo o constituyente? ¿Acaso el parlamento sería, en algún caso, el interlocutor válido para las representaciones extranjeras? Puede plantearse el debate, no siendo el ejemplo más frecuente en que un Estado reconozca o no reconozca la legitimidad de una asamblea legislativa o constituyente. Carece de sentido práctico, más allá de las intenciones de dar señales políticas o de ejercer presiones diplomáticas, objetivo último que persiguen las declaraciones de los países en el caso de estudio, pero que desde un punto de vista jurídico revisten una lógica legal poco frecuente.

De las declaraciones oficiales se extrae que Argentina, Chile, Costa Rica, Brasil, España, Perú, Canadá, Colombia, México, Panamá, Paraguay, Estados Unidos y la Unión Europea desconocieron de forma expresa los resultados de las elecciones de la ANC (CNN Español, 2017), extendiendo la nulidad del proceso hasta al propio órgano ${ }^{14}$.

Resulta jurídicamente curioso el no reconocimiento de la Asamblea Constituyente venezolana por parte de terceros Estados, así como también que reconozcan la legitimidad de la Asamblea Nacional. El punto de estas manifestaciones, claro está, es

\footnotetext{
${ }^{14} \mathrm{Si}$ bien existieron declaraciones de apoyo a las elecciones del 31 de julio y a la ANC, por parte de Bolivia, El Salvador, Nicaragua, Rusia y Siria, las mismas contenían un reconocimiento tácito y no expreso.
} 
esencialmente político, pero el acto per se quedará como un antecedente peculiar en el derecho internacional en que una asamblea representativa fue reconocida o no reconocida por la comunidad internacional en un contexto en donde no existen facciones enfrentadas por el dominio territorial efectivo, que está claramente en poder de una de las partes, sino por la titularidad en el ejecutivo. La situación en ese sentido se asemeja en este caso más al reconocimiento de gobiernos en el exilio, pero aún en esos casos se vincula el reconocimiento de gobierno a una autoridad que pretende ejercer el gobierno efectivo y está impedido de hacerlo y no a un órgano dentro de la institucionalidad del Estado.

\section{4. El Grupo de Lima y su actuación}

Paralelamente, el 8 de agosto de 2017, cuatro días después de la primera sesión de la ANC, un conjunto de países alineados en el rechazo a la controversial institución conformaron el denominado Grupo de Lima tras una declaración donde se manifestaba la "decisión de no reconocer a la Asamblea Nacional Constituyente, ni los actos que emanen de ella" (Declaración de Lima, 2017) ${ }^{15}$. Si bien este punto es importante, ubicamos el análisis de este grupo de forma separada al asunto del reconocimiento de la ANC debido a que este no es el punto central de esta coalición. Todos los países miembros del Grupo de Lima ya habían individualmente calificado a la ANC como órgano ilegítimo, por lo que el punto señalado pierde relevancia.

El objetivo de este abordaje es la legalidad del resto de los contenidos, tanto de la propia Declaración de Lima como de los actos de estos Estados coordinados en el marco de este Grupo. ¿Son legales estas instancias multilaterales de concertación política? Ciertamente es así. Al menos a priori, una agenda conjunta de Estados con un objetivo en común y que se congregan para coordinar acciones en torno a dicho interés mutuo no resulta en sí una organización ilegal en virtud del derecho internacional. No obstante, si bien la forma es ajustada a derecho, no necesariamente tiene que serlo el contenido.

La cuestión fundamental es el objeto de interés y las acciones de este Grupo. Diversos puntos de la Declaración de Lima (2017) pueden interpretarse como formulados al

\footnotetext{
${ }^{15}$ Documento conjunto de Argentina, Brasil, Canadá, Chile, Colombia, Costa Rica, Guatemala, Honduras, México, Panamá, Paraguay y Perú.
} 
borde del principio de no intervención del derecho internacional ${ }^{16}$. ¿Es posible justificar jurídicamente que, en aras de la protección de los derechos de los venezolanos, se proceda a presionar políticamente al gobierno? Es comprensible la acción en el marco de la OEA y del Mercosur en donde se encuentra pactada la existencia de una institucionalidad democrática como requisito para la su pertenencia a esas organizaciones. En cambio, no resulta igual el fundamento legal para que un grupo de Estados ejerza presiones políticas para la consecución de sus objetivos dentro de la jurisdicción de otro Estado soberano. Una supuesta ausencia de democracia no configura un argumento suficiente para los actos y discursos intervencionistas sin un respaldo jurídico que lo haya establecido (Roncagliolo, 2015).

En este sentido, el derecho internacional regional es claro y contundente en sus estipulaciones. La Carta de la OEA mandata en su artículo 19 que:

(N)ingún Estado o grupo de Estados tiene derecho a intervenir, directa o indirectamente, y sea cual fuere el motivo, en los asuntos internos o externos de cualquier otro. El principio anterior excluye no solamente la fuerza armada, sino también cualquier otra forma de injerencia o de tendencia atentatoria de la personalidad del Estado, de los elementos políticos, económicos y culturales que lo constituyen.

La conformación de este principio tiene especial relevancia en el continente, lo que lo torna doblemente más importante en el caso de estudio. El mismo no ha tomado esta forma de manera caprichosa, es el resultado de las convulsiones en América y en las fricciones constantes entre vecinos a lo largo de su historia (Brotóns, 2007, pp. 138140). Solamente la OEA misma puede establecer un quiebre a esta disposición cuando hace jugar la Carta Democrática y con los límites que ella establece. Pero no un grupo parcializado de países por fuera de la organización.

Por ello, además de la potencial ilegalidad, la actuación del Grupo de Lima demuestra también una falta de conciencia histórica regional al ignorar la centralidad del principio de no intervención -y sus consecuencias más inmediatas y perentorias- en las relaciones entre las repúblicas americanas. A cambio de la búsqueda de una solución alineada con lo que ellos pretenden para la crisis venezolana, se dejan de lado las consecuencias perniciosas del medio empleado para la institucionalidad continental.

\footnotetext{
${ }^{16}$ Los puntos 2, 4, 6, 8, 9, 10, 12, 15 y 16 de la Declaración de Lima resultan al menos
} debatibles. 


\section{SEgunda CRISIS INSTITUCIONAL}

El 24 de enero de 2018, la ANC aprobó un decreto para adelantar las elecciones presidenciales, previstas para finales del año (BBC Mundo, 2018). La autoridad electoral venezolana fijó finalmente el 20 de mayo como el día de los comicios. Cabe señalar que las principales figuras de la oposición, como Henrique Capriles y Leopoldo López, así como partidos políticos al completo, fueron inhabilitados para participar como candidatos por el poder electoral de la forma en que pretendía hacerlo (Ministerio de Relaciones Exteriores del Brasil, 2018). Este hecho, sumado a la percepción de falta de garantías electorales y el poco tiempo que existía hasta la primera fecha propuesta (inicialmente, solo seis semanas los separaban de las elecciones) (Reuters, 2018), hizo que la convocatoria fuera rechazada por la mayoría de la oposición y renunciara a presentarse en los comicios.

Las respuestas internacionales no se hicieron esperar. El Grupo de Lima declaró que rechazaba el adelanto de los comicios, manifestando que unas elecciones que no fueran transparentes y creíbles con la participación de todos los actores políticos y con observación y estándares internacionales, carecerían de legitimidad y credibilidad. Exhortaba al gobierno venezolano a presentar un calendario electoral concertado con la oposición y que permitiera el cumplimiento de estas características (Grupo de Lima, 2018a). En el mismo sentido se expresaron la OEA (2018a) y la Unión Europea (2018a).

A pesar de esto, las elecciones tuvieron lugar en mayo y, tras las mismas se reiteraron las declaraciones de apoyo y rechazo a la legitimidad de los resultados (Grupo de Lima, 2018b; Unión Europea, 2018b), que anunciaron a Nicolás Maduro como el abrumador ganador en unas elecciones históricas en materia de ausentismo popular (García Marco, 2018).

\section{1. La reacción de la OEA}

Particularmente interesante, en este contexto, fue la declaración de la Asamblea General de la OEA, al menos desde el punto de vista de sus efectos, que desconoció la legitimidad del proceso electoral y urgió al gobierno venezolano a instaurar el Estado de Derecho (OEA, 2018b).

Por otro lado, la retórica del Secretario General de esta organización, Luis Almagro, no se moderaba con eufemismos. El 21 de mayo, tras las elecciones presidenciales, 
calificó como dictador a Nicolás Maduro y como régimen totalitario a su gobierno (OEA, 2018c). El 21 de agosto llamó a las autoridades competentes del hemisferio a desconocer los actos del TSJ, argumentando su carácter ilegítimo, especialmente en sus pedidos de extradición (OEA, 2018d). En el mismo comunicado expuso cuáles eran las "únicas instituciones democráticas" de Venezuela de forma taxativa, siendo estas la Asamblea Nacional (por haber sido conformada en virtud de las elecciones de 2015); el Tribunal Supremo de Justicia en el exilio (por sus magistrados designados por la AN); y la Fiscalía General en el exilio.

Respecto de estas manifestaciones podría argumentarse que, dado el derecho internacional regional en materia de democracia, el Secretario General de la OEA tiene la potestad de señalar las contravenciones manifiestas a esta forma de gobierno en el continente, o la facultad de recomendar a otros Estados líneas de acción con respecto a un Estado que viola sus obligaciones democráticas. No obstante, también podría decirse que, si bien la organización y su Secretario General tienen la potestad de declarar rupturas del orden democrático en un Estado, en ningún momento tienen la posibilidad de determinar si los Estados Miembros deben o no tener relación con los órganos de gobierno del Estado señalado. La ausencia manifiesta de una democracia no supone la ineficacia del gobierno. Es decir, que los órganos (en este caso concreto, el TSJ) resulten "ilegítimos", desde la perspectiva de la OEA, no implica que sean ineficaces, que es en definitiva una importante condición para el mantenimiento de las relaciones entre Estados.

\section{2. La proclamación de Juan Guaidó}

Varios meses después de la elección, el 10 de enero de 2019, haciendo caso omiso de las manifestaciones anteriores respecto de la validez de las elecciones, Nicolás Maduro juró su nuevo período presidencial ante el TSJ. El acto fue recibido otra vez con el rechazo de Estados Unidos, Canadá y el Grupo de Lima (Reuters, 2019a). Nuevamente, el hecho de mayor interés fue la resolución del Consejo Permanente de la OEA del mismo día, en la que no se reconoce la legitimidad del período de Nicolás Maduro a partir del 10 de enero de 2019 utilizando el vocablo "régimen", se insta al gobierno a realizar nuevos comicios con garantías electorales y se insta a los Estados Miembros de la organización a "adoptar (...) las medidas diplomáticas, políticas, económicas y financieras que consideren apropiadas para contribuir a la pronta restauración del orden democrático en Venezuela" (OEA, 2019a, párr. 3). Todo esto 
sin que Venezuela haya sido suspendida por una alteración del orden democrático en virtud de la Carta Democrática, para lo cual nunca existió la mayoría necesaria de dos tercios $^{17}$.

Días más tarde, la Asamblea Nacional de Venezuela declaró a Nicolás Maduro como "usurpador" del poder legítimo de la república, asumiendo las competencias del Poder Ejecutivo en virtud de las disposiciones constitucionales según las cuales se configuraría un "abandono del cargo" por parte de Maduro (Europa Press, 2019). Posteriormente el presidente del órgano legislativo, Juan Guaidó, se autoproclamó públicamente como presidente interino del país siguiendo lo que dice la Constitución venezolana para el caso de ausencia o abandono del cargo por parte del Presidente (Armas y Pons, 2019) ${ }^{18}$.

Frente a esta particular coyuntura la comunidad internacional se alineó en tres bandos. Estados y organizaciones internacionales que respaldaban a Juan Guaidó y la Asamblea Nacional; aquellos que respaldaban a Nicolás Maduro y su gobierno; y aquellos que se mantenían neutrales.

\section{3. El reconocimiento de Juan Guaidó}

\footnotetext{
17 Nos resulta particularmente interesante realizar una anotación respecto a los distintos sistemas de votación dentro de la OEA, que configuran la manera en que se forma la voluntad de la organización y sus consecuencias. Tanto la Asamblea General como el Consejo Permanente toman decisiones por mayoría absoluta de votos, incluyéndose en esta categoría las resoluciones declarativas tales como la CP/RES. 1078, AG/RES. 2929, o la recién citada CP/RES. 1117. Por otro lado, la Asamblea General requiere dos tercios de votos, una mayoría especial, para suspender a uno de sus Estados Miembros en sus derechos. Si bien podría argumentarse que existe una lógica detrás, según la cual las sanciones sobre un Estado deberían ser progresivas, por lo tanto una declaración "punitiva" que recomiende medidas a un Miembro que violente sus obligaciones democráticas, resulta más sencilla de obtener (en cuanto a los votos necesarios) que una suspensión del estatus de Miembro, lo cierto es que este sistema puede generar una curiosa paradoja. Este es el caso de lo que ha ocurrido con el caso venezolano. La organización puede declarar abiertamente que uno de sus miembros ha roto su orden democrático (1078), puede denominar a su gobierno "régimen" e instar a la adopción de medidas en su contra (1117), pero se encuentra paralizada para suspenderlo en sus derechos por no llegar a la mayoría de dos tercios, muy a pesar de que supuestamente contravenga las principales y más esenciales normas democráticas que la organización pregona con efusividad. Esta situación además puede percibirse a la inversa: ¿es correcto adoptar por mayoría simple una decisión sobre el status democrático de un gobierno, cuando la Carta Democrática requiere de dos tercios para que sea declarado y suspendido por tal motivo? Más adelante se volverá sobre este tema en el punto 4 de esta parte.

${ }^{18} \mathrm{La}$ validez de la fundamentación jurídico- constitucional de la proclamación de Guaidó será considerada en el punto siguiente.
} 
Los argumentos de derecho internacional empleados en favor del gobierno de Nicolás Maduro, esgrimidos por Estados tales como Rusia o China ${ }^{19}$, se fundamentan en los principios de igualdad soberana y no intervención en los asuntos domésticos de los Estados. Si bien la retórica de todos los gobiernos que se manifestaron en apoyo de Maduro o de Guaidó se han referido a la "legitimidad" de uno u otro (cuya consideración es política y no jurídica), lo cierto es que la posición a favor del oficialismo venezolano tiene en teoría un anclaje más directo en el derecho internacional. Nos referimos específicamente a que el reconocimiento de Nicolás Maduro y su gobierno no sería necesario si nos atenemos a ciertas reglas del instituto de reconocimiento de gobierno: sin haber habido un cambio en las figuras de autoridad y manteniendo el control efectivo del aparato estatal, el reconocimiento no procedería dado que se entiende que quien gobernó lo continuará haciendo. Naturalmente, esto no supone un juicio de valor sobre la legitimidad democrática del gobernante, pero es el principio que se ha aplicado a buena parte de los regímenes de facto en las últimas décadas (Shaw, 2008, pp. 454-459). En el caso de Maduro esto presupone naturalmente (y simplemente), considerar al acto eleccionario que lo mantiene en el poder como válido.

En cambio, el caso del reconocimiento de Juan Guaidó como presidente de Venezuela requiere un análisis de mayor profundidad. Tanto la oposición venezolana, en lo interno, como los Estados que se han manifestado a favor de Guaidó, en lo internacional, sostienen la invalidez de las elecciones presidenciales de 2018 y por lo tanto, del período de gobierno de Nicolás Maduro de 2019 a 2025. Conjuntamente con esto aplican el artículo 233 de la Constitución de Venezuela, que señala al presidente de la Asamblea Nacional como el encargado temporal de la máxima magistratura en el caso de una "falta absoluta" del titular. El mismo artículo incluye en este término, entre otros, a la figura del abandono del cargo "declarado como tal por la Asamblea Nacional". Quedará para los especialistas en derecho constitucional venezolano la interpretación de esta fundamental disposición dado que no queda claro el alcance del concepto de "abandono del cargo" ni en qué circunstancia es válida y suficiente su declaración por parte del parlamento. ¿Nicolás Maduro abandonó el cargo? ¿O se busca cubrir un supuesto vacío legal con la aplicación de este artículo, con intencionalidad política? Una interpretación favorable al argumento del abandono no

\footnotetext{
${ }^{19}$ Ver punto 4.3 de este trabajo.
} 
parece pasar la prueba de la realidad y sólo puede entenderse en un marco de crisis institucional y política donde se consideraban inválidas las elecciones realizadas anteriormente.

En materia de derecho internacional, todas estas reflexiones pertenecen a la esfera de jurisdicción privativa del Estado, por lo que podría responderse que cualquier controversia interna en cuanto a las normas aplicables a esta situación deberá ser dilucidada por los venezolanos. No obstante, también podría argumentarse que, dado la prolongación de esta situación en la que dos gobiernos reclaman la titularidad del aparato estatal y ninguno se impone sobre el otro, ya sea por medios populares, armados o institucionales, la comunidad internacional puede tener un genuino interés (y una genuina confusión) sobre qué gobierno debe reconocerse y/o posee el real y efectivo control del Estado. En cualquier caso, es indudable que al día de hoy el control efectivo del aparato estatal está en manos de Maduro y que existieron y existen otros intereses que se buscan proteger o propiciar o derechos que ser pretenden tutelar, cuando se promueve el reconocimiento de Guaidó como presidente encargado de Venezuela.

\section{4. Gustavo Tarre: el problema de la representación en la OEA}

El 10 de abril de 2019, con la Venezuela de Maduro ya en vías de retirarse de la $\mathrm{OEA}^{20}$, la organización resolvió aceptar al representante Gustavo Tarre, designado por la Asamblea Nacional de Venezuela, como embajador del país ante la organización "hasta que se celebren nuevas elecciones y el nombramiento de un gobierno democráticamente electo" (OEA, 2019b, nota al pie 1). Esto significaba desconocer al representante del gobierno de Maduro y aceptar al de representante de Guaidó, al menos de forma transitoria.

Varios Estados, en minoría, fueron críticos de esta resolución del Consejo Permanente de la Organización, por diferentes motivos.

\footnotetext{
${ }^{20}$ Venezuela se retiraría de la OEA unos días después, el 27 de abril de 2019, luego de haber iniciado el proceso de retiro dos años antes. Pese a que la República Bolivariana de Venezuela oficializó su desvinculación con el ente regional, el autoproclamado presidente encargado del país, Juan Guaidó, nombró previamente a Gustavo Tarre como su representante ante la OEA, suspendiendo el trámite de denuncia de la carta de Bogotá y retiro de la organización que había empezado el Gobierno anterior, lo que generó la peculiar situación que se describe en este párrafo.
} 
En primer lugar, naturalmente, la República Bolivariana de Venezuela, quien sostuvo en primer lugar que "la OEA no tiene autoridad para reconocer o desconocer a los gobiernos de sus Estados Miembros" (OEA, 2019b, nota al pie 1).

$\mathrm{Y}$ en esta misma línea agrega que la única medida coercitiva que se encuentra jurídicamente habilitada a aplicar y que podría dar lugar al cambio en la titularidad del representante, sería una ruptura del orden democrático -como indica la Carta Democrática Interamericana, en su artículo 21- cuando la Asamblea General de la OEA tiene la facultad de suspender a dicho Estado en su participación por esa causa, no siendo esta la situación actual. Por lo tanto, el hecho de que la organización haya desconocido a los representantes de Nicolás Maduro y aceptado a los representantes de Juan Guaidó es jurídicamente equivocado:

El único modo que los representantes legítimos del Estado Venezolano, miembro pleno de esta organización, con todos los derechos ejercidos por más de 70 años, el único modo, para que se levanten de la silla de Venezuela, sin violar la ley internacional, sin violencia, sin trampa, sin fraude, sin manipulación jurídica y sin arbitrariedad, es que la Presidencia del Consejo Permanente de la OEA tenga en su poder la resolución aprobada por la Asamblea General Extraordinaria de la OEA donde 24 Estados Miembros (esto es los dos tercios de los Estados miembros) votaron por la suspensión de los derechos del Estado Venezolano en esta Organización. Sin esta resolución de la Asamblea General, todo acto es nulo y significa el fin de la vigencia de la Carta Fundacional (OEA, 2019b, nota al pie 1 párr. 8).

Dos comentarios debemos hacer al respecto: en primer lugar, que es correcto que la organización requiere necesariamente conocer el gobierno que representa efectivamente al Estado Miembro, con el propósito de aceptar las credenciales del embajador delegado; en segundo lugar, que dicho reconocimiento de gobierno no debía darse en el caso concreto a estudio.

En efecto, no existía una ruptura del orden democrático en Venezuela declarada en base a la Carta Democrática, lo cual no justifica un reconocimiento de otro gobierno.

A esto debe agregarse además que el Consejo Permanente de la OEA (órgano que adoptó la resolución) carece de facultades para pronunciarse sobre el tema que 
resuelve ya que no le ha sido otorgado ningún mandato para hacerlo. El Artículo 82 de la Carta de la OEA establece que el Consejo Permanente únicamente puede conocer de los asuntos que le encomienden la Asamblea General o la Reunión de Consulta de Ministros de Relaciones Exteriores, lo que no existía en la especie. Y no hay por supuesto disposiciones específicas establecidas en la Carta que le otorguen facultades al Consejo Permanente para tomar per se decisiones sobre el reconocimiento de gobiernos y de representantes de Estados Miembros.

Las notas al pie que otros Estados realizaron sobre la resolución 1124 van en el mismo sentido que los argumentos jurídicos que acabamos de expresar, de denuncia de una manipulación interna de la organización no conteste que las normas de la Organización y del derecho internacional. ${ }^{21}$ Como señala a nuestro juico correctamente el representante de México:

La institucionalidad de la OEA, su estructura, su vinculación con los Estados Miembros y la correcta conducción de sus funciones legalmente establecidas, se ven lesionadas por esta resolución. El mal precedente que se crea es peligroso no sólo para el futuro de la Organización, sino para la correcta aplicación del derecho internacional y la relación entre Estados (OEA, 2019b, nota al pie 3).

\section{ACciones de LA Comunidad InTERnACIONAL TENDIENTES A SOlUCIONAR LA CRISIS}

Tras la proclamación de Juan Guaidó y el agravamiento de la crisis institucional en Venezuela, han surgido distintos mecanismos en el seno de la comunidad internacional con el objetivo de encontrar una solución ${ }^{22}$.

\section{1. El Grupo de Lima}

El 4 de febrero de 2019, el Grupo de Lima respaldó al recientemente proclamado presidente Juan Guaidó y su gobierno y se le daba la bienvenida paradójicamente a

${ }^{21}$ En el mismo sentido se manifestaron (en orden de aparición en el documento) El Salvador, México, Bolivia, Nicaragua, Uruguay, Antigua y Barbuda, San Vicente y las Granadinas, y Guyana.

${ }^{22}$ Los mecanismos abordados en este punto no incluyen la mediación de Noruega, también denominada "negociación de Oslo". Esto se debe fundamentalmente, a su efímera existencia, dado que tuvo lugar entre mayo y julio de 2019, cuando los representantes del gobierno de Nicolás Maduro se retiraron de la mediación. Véase Ellsworth y Sequera, 2019; Reuters, $2019 b$. 
Venezuela dentro del grupo. La declaración de la instancia señalaba, además, que se aceptarían a los representantes del nuevo presidente en cada uno de los países miembros del grupo. Por último, y siendo el pasaje más interesante de todo el documento, los Estados observaron que "las iniciativas de diálogo propiciadas por diversos actores internacionales fueron manipuladas por el régimen de Maduro, transformadas en maniobras dilatorias para perpetuarse en el poder" (Grupo de Lima, 2019a, párr. 4). Asimismo, declaraban que toda iniciativa política o diplomática para solucionar la crisis debía tener por eje la "hoja de ruta" demarcada por la Asamblea Nacional y el presidente Juan Guaidó. Resulta ostensible que la propuesta del Grupo de Lima resulta menos dialoguista que otros mecanismos negociadores que se verán a continuación, resultando más un grupo de apoyo a Guaidó.

El 25 de febrero de 2019, el Grupo de Lima emitió una declaración que posteriormente fue referida al Consejo de Seguridad de Naciones Unidas ${ }^{23}$. En el documento se denunciaba que el gobierno de Nicolás Maduro impidió "el ingreso de artículos de primera necesidad y la asistencia internacional, mediante actos de represión violenta que ocasionaron múltiples heridos y muertos en la frontera con Colombia y Brasil" (Grupo de Lima, 2019b, párr. 1). Además, se afirmaba que el gobierno intencionadamente sometía a su población a una sistemática privación de alimentos y medicinas (Grupo de Lima, 2019b). El presentar este asunto ante el Consejo de Seguridad demuestra que la estrategia del grupo para solucionar la crisis es la del rechazo, el aislamiento y la presión sobre el gobierno de Nicolás Maduro, con el objetivo de lograr su salida.

\section{2. EI Grupo Internacional de Contacto sobre Venezuela}

A principios de 2019 se articularon dos instancias distintas, en su enfoque y composición, al Grupo de Lima. Por un lado, el Mecanismo de Montevideo que apelaba a una aproximación moderada a la solución de la crisis en Venezuela, centrándose en el diálogo entre oficialismo y oposición para alcanzar una salida negociada (Infobae, 2019a). Por otro lado, el Grupo de Contacto Internacional propulsado por la Unión Europea y algunas naciones latinoamericanas, que se fundamentaba tanto en la obtención de mecanismos eficaces para lograr canalizar la

\footnotetext{
${ }^{23}$ Ver punto 3.c de este trabajo.
} 
ayuda humanitaria internacional, así como un énfasis en la necesidad de elecciones libres y transparentes en el país (Banchón, 2019).

Ambas instancias fueron cobrando relevancia a medida que la bicefalia de Venezuela evidenciaba una clara parálisis de la crisis institucional, que perpetraba el deterioro de la situación humanitaria y económica.

El mecanismo recibió el apoyo del gobierno de Nicolás Maduro para encontrar el diálogo político con la oposición. Sin embargo, los representantes de la Unión Europea plantearon la necesidad de emitir un comunicado por parte del mecanismo con una retórica más cerrada, lo que supuso el abandono del grupo (TeleSUR, 2019). A partir de entonces, la instancia superviviente fue el Grupo Internacional de Contacto que fue ganando apoyos a medida que más Estados americanos fueron sumándose a la iniciativa (Infobae, 2019b).

Finalmente, el 15 de setiembre de 2020, frente a la perspectiva de nuevos comicios parlamentarios en Venezuela llamados por el gobierno de Maduro (ver infra punto VII "Situación actual"), el grupo de Contacto se volvió a reunir de forma virtual llegando a la conclusión de que en estos comicios previstos para el 6 de diciembre "no se cumplen las condiciones para un proceso electoral transparente" (Infobae, 2020a, párr. 1).

Creemos que el mecanismo ideado se ajusta a los instrumentos de solución pacífica de las controversias promovidos por el derecho internacional. Una instancia de negociación diplomática que considere a todos los involucrados en el conflicto interno de Venezuela parece ser además el camino más adecuado para tener éxito.

\section{3. EI Consejo de Seguridad de Naciones Unidas}

Frente a una situación de parálisis negociadora con ostensibles contravenciones de derecho internacional, tanto por parte de terceros Estados que buscan imprimir una particular voluntad a Venezuela como por parte del gobierno de Nicolás Maduro, acusado de violar los derechos humanos de las personas en su país, no resultaba muy difícil esperar alguna forma de actuación de la autoridad competente en materia de amenazas a la paz y la seguridad internacional: el Consejo de Seguridad de las Naciones Unidas (CSNU). 
Desde 2017 el organismo ha llevado adelante reuniones formales e informales sobre el asunto venezolano. El tema ha sido introducido al Consejo a petición de Estados Unidos, Rusia y la Unión Europea, en diversas ocasiones. Resulta evidente que existe una parálisis del organismo con respecto a Venezuela donde los "cinco grandes" apoyan a bandos opuestos del conflicto y, por ende, no comparten medidas similares para su solución. Por un lado, Rusia y China apoyan al gobierno de Nicolás Maduro, mientras que Estados Unidos, Reino Unido y Francia favorecen a la oposición y la presidencia interina de Juan Guaidó.

Para no extendernos en el contenido de los debates -al menos de las reuniones públicas- abordaremos a continuación las únicas dos resoluciones que fueron propuestas en el CSNU sobre Venezuela en esta cuestión. Ambos proyectos competían simultáneamente y se sometieron a votación el 28 de febrero de 2019. Naturalmente, ambos recibieron el veto de sus contrapartes por lo que ninguna de las resoluciones fue adoptada.

El proyecto de resolución propuesto por Estados Unidos (CSNU, 2019a) hace referencia en su preámbulo a la resolución 2929 (ilegitimidad de las elecciones presidenciales de 2018) y 1117 (ilegitimidad del período presidencial de Nicolás Maduro a partir del 10 de enero de 2019), ambas de la OEA. Asimismo, señala la autoridad constitucional de la Asamblea Nacional y sus esfuerzos para recuperar la democracia. Expresa fuerte preocupación por las acciones del gobierno que "han causado el colapso económico, forzando a millones de venezolanos a abandonar su país como refugiados o migrantes" (CSNU, 2019a, párr. 7). En su parte declarativa, afirma que las últimas elecciones presidenciales no fueron justas ni libres y mandata el llamado a nuevos comicios con garantías, transparencia y observadores internacionales. Adicionalmente, solicita los buenos oficios del Secretario General de Naciones Unidas para el acercamiento del gobierno y la oposición, con el propósito de restaurar la democracia y el Estado de Derecho de forma pacífica. Subraya la necesidad de garantías para la seguridad de los parlamentarios de la Asamblea Nacional y de toda la oposición política. Finalmente, sostiene la necesidad de evitar mayor deterioro de la situación humanitaria, facilitando el ingreso y distribución de la asistencia internacional a todo el territorio del país.

La redacción del proyecto es coherente con la posición de Estados Unidos. Podría decirse en su contra que la atribución de responsabilidades es parcial y arbitraria, que 
evita cualquier mención de las presiones internacionales a las que se somete al gobierno de Venezuela, muchas de ellas de dudosa legalidad. De igual forma, puede constatarse que la resolución se alinea con la posición mayoritaria del continente americano sobre la ilegitimidad del régimen de Nicolás Maduro, que señala y castiga la comisión de sistemáticas violaciones de derechos humanos contra la población civil venezolana, tanto por el uso excesivo de la fuerza como por la privación de alimentos y medicamentos, y que apunta esencialmente a detener la grave crisis humanitaria que aquejaba no solo al país sino a la región que se veía obligada a recibir a millones de refugiados.

El proyecto de resolución propuesto por Rusia (CSNU, 2019b) en su preámbulo, expresa preocupación por las amenazas del uso de la fuerza contra la integridad territorial e independencia política de Venezuela. Manifiesta también preocupación sobre los intentos de intervenir en asuntos que son esencialmente de jurisdicción doméstica y privativa del Estado venezolano. En ninguno de los casos atribuye responsabilidades. En su parte dispositiva, urge a la resolución de la situación actual mediante medios pacíficos bajo el respeto absoluto de la soberanía, la integridad territorial y el derecho de libre determinación del pueblo venezolano. Apoya todas las iniciativas que tengan por objetivo la solución política de la situación, incluyendo el Mecanismo de Montevideo -mencionado explícitamente-, mediante un "genuino e inclusivo proceso de diálogo nacional" (CSNU, 2019a, párr. 6). Finalmente, reafirma el protagonismo del gobierno venezolano en la iniciación, organización, coordinación e implementación de las asistencias humanitarias.

Resulta muy clara la orientación política de esta resolución y sus objetivos. El documento en ningún momento pone en duda la legitimidad del gobierno de Nicolás Maduro. Tampoco menciona los conflictos intestinos de legitimidad, especialmente el rol principal que tiene la Asamblea Nacional. Si bien señala en algunos párrafos la Constitución venezolana, evade los cuestionamientos que se le ha hecho al gobierno sobre su grado de apego a la misma. Podría criticarse también la ausencia de menciones a las conductas represivas ejecutadas por el gobierno y resulta curioso que deje en manos de éste la implementación de las ayudas humanitarias cuando las había bloqueado días antes, disparando la proposición de estas dos resoluciones que aquí analizamos. 
Por otro lado, el instrumento prioriza los principios de derecho internacional de soberanía del Estado y no intervención y toma una postura dialoguista para la solución del conflicto. Asimismo, condena las amenazas a la fuerza y presiones injerencistas de otros Estados que, si bien no las menciona directamente, sí advierte sobre su existencia y las rechaza sin referir a las formas de "intervención" de la propia Rusia o de Cuba en Venezuela, aunque hayan sido a instancias de parte.

Resulta indudable que la resolución propugnada por Estados Unidos no acepta la situación política actual en Venezuela y desconoce la legitimidad del gobierno de Nicolás Maduro buscando un posicionamiento activo de la comunidad internacional respecto del conflicto. Por otro lado, la resolución defendida por Rusia promueve y perpetúa el statu quo político actual en el país, ignora por completo a la oposición, a la manifiesta represión política y a las violaciones de derechos humanos, buscando en contrapartida un posicionamiento diferente de la comunidad internacional ante el conflicto en cuestión.

\section{Violaciones DE DERECHOS humANOS}

El deterioro gradual pero constante de la economía venezolana sumado a la grave crisis política e institucional a la que hemos hecho referencia en párrafos anteriores, derivó en su momento en la expresión del malestar ciudadano en las propias calles del país.

Esta expresión tomó la forma de multitudinarias protestas en contra del gobierno. Aunque se mantienen de forma intermitente hasta la actualidad (Infobae, 2020b), las mismas encontraron su apogeo en dos momentos: las movilizaciones de 2014 y 2017.

Entre el 12 de febrero y el 8 de mayo de 2014 se sucedieron una serie de movilizaciones populares, originadas en los movimientos estudiantiles cuyo objetivo era obtener la renuncia de Nicolás Maduro y su gabinete dada la situación de escasez de productos básicos y la alta inflación que asolaba el país (ACNUDH, 2014a; ACNUDH, 2014b; Zamorano, 2014). Si bien esta ola de protestas se encuentra cronológicamente por fuera de los márgenes de este trabajo, consideramos importante mencionarla dado que fue el primer gran levantamiento masivo de la población contra el gobierno venezolano, tras el fallecimiento de Hugo Chávez. 
Aunque existen numerosas fuentes de información sobre lo sucedido en este tema, tanto de medios de prensa como documentos oficiales, este trabajo se centrará en los informes presentados por la Oficina del Alto Comisionado de Naciones Unidas para los Derechos Humanos (ACNUDH), así como los documentos referenciados en estos por entender que se trata de una fuente de alta credibilidad e imparcialidad y que recoge de manera exhaustiva la información disponible. Asimismo, se mencionará también el último informe del Consejo de Derechos Humanos de setiembre de 2020.

\section{V.1. Informe del ACNUDH de 2017}

La ola de protestas que ocurrió en 2017 fue detonada por las sentencias N¹55 y 156 del TSJ a finales de marzo y se prolongaron hasta julio, tras las elecciones de la ANC (Hernández, 2017). Cuatro meses de protestas diarias sacudieron al país. Durante ese tiempo el gobierno respondió con el uso de sus fuerzas de seguridad, tanto reprimiendo a los manifestantes por la fuerza en los espacios públicos, como mediante arrestos y detenciones arbitrarias.

En junio de 2017 la Oficina del Alto Comisionado ${ }^{24}$ creó un equipo especial destinado a investigar las presuntas violaciones de derechos humanos ocurridas durante las protestas masivas. Tal como lo señala el informe (ACNUDH, 2017), el gobierno venezolano negó la autorización de los oficiales de Naciones Unidas para ingresar al país e investigar in situ. Sin embargo, la Oficina del Alto Comisionado logró recabar de forma extensiva la información necesaria para el informe, mediante monitoreo a distancia, numerosas entrevistas personales y la recepción de información proveniente de variedad de instituciones públicas y organizaciones no gubernamentales.

El informe asegura que la Oficina documentó "la existencia de violaciones generalizadas de los derechos humanos por parte de las autoridades nacionales en el contexto de las manifestaciones realizadas en todo el país, violaciones que tienen por objeto frenar cualquier tipo de protesta contra el Gobierno". Además, se "constató que las fuerzas de seguridad han utilizado sistemáticamente fuerza excesiva y realizado detenciones arbitrarias de las personas que participan en las manifestaciones". Finalmente, se "documentó la existencia de patrones de malos tratos, que en

${ }^{24}$ El Alto Comisionado de las Naciones Unidas para los Derechos Humanos Zeid Ra'ad Al Hussein redactó los informes sobre Venezuela de 2017 y 2018. El informe de 2019 estuvo a cargo de la Alta Comisionada Michelle Bachelet, quien ocupa la oficina desde el 1 de setiembre de 2018. 
ocasiones podrían llegar a constituir tortura, malos tratos y violaciones graves del derecho al debido proceso por parte de las autoridades venezolanas" (ACNUDH, 2017, parte ii).

Sin ánimo de extendernos en materia de normativa de derechos humanos internacionalmente protegidos resulta necesario recordar que la protección de los mismos fue plasmada en numerosos instrumentos legales ${ }^{25}$, los que también se ven amparados en el derecho internacional consuetudinario (Barcelona Traction, 1970, párr. 34; Crawford, 2012, pp. 642-643; Shaw, 2008, p. 275), por lo que sus formas más evidentes (las normas consideradas de jus cogens) se encuentran protegidas por la comunidad internacional, aunque el Estado infractor no forme parte de ningún tratado en esta materia (Crawford, 2012, p. 595).

No obstante, tal como lo señala la Comisión de Derecho Internacional de Naciones Unidas (AGNU, 2001, art. 2), para que exista responsabilidad del Estado por el incumplimiento de una norma internacional deben de constatarse dos elementos fundamentales: (1) la violación de dicha obligación y (2) debe de ser atribuible al Estado.

Este es según la ACNUDH el caso de los eventos acaecidos en Venezuela en 2017, los cuales son detallados en el informe mencionado y donde se constata tanto la violación de derechos humanos y libertades fundamentales básicas de los manifestantes, como su realización de forma sistemática y deliberada por agentes del Estado, en especial las fuerzas de seguridad.

La investigación de la Oficina del Alto Comisionado constató y documentó, durante las protestas masivas, el uso excesivo de fuerza para su represión ${ }^{26}$, muertes violentas de manifestantes y transeúntes ${ }^{27}$, violación del derecho de integridad física ${ }^{28}$,

25 Pacto Internacional de Derechos Económicos, Sociales y Culturales (1966); Pacto Internacional de Derechos Civiles y Políticos (1966), su primer Protocolo Facultativo (1966) y su segundo Protocolo Facultativo (1989); Convención Americana sobre Derechos Humanos (1969). Estos son los ejemplos más relevantes para el caso concreto.

${ }^{26}$ Se constató la infracción de los estándares nacionales e internacionales del uso de fuerza por parte de los agentes de seguridad, especialmente mediante el incumplimiento de los principios de proporcionalidad, necesidad y progresividad (ACNUDH, 2017, pp. 8-10).

${ }^{27}$ Se asegura que las fuerzas de seguridad estatales emplearon armamento letal, tales como "perdigones, 'metras' (canicas) y piezas de varilla metálica". Se constató la muerte de al menos 14 manifestantes que fueron alcanzados por estas municiones (ACNUDH, 2017, p. 14).

28 "El Ministerio Público inició investigaciones sobre al menos 1958 denuncias por lesiones sufridas en el contexto de las manifestaciones. Según esta institución aproximadamente en el 60 por ciento de casos los presuntos autores eran miembros de las fuerzas de seguridad, 
allanamientos ilegales y violentos ${ }^{29}$, destrucción de la propiedad privada ${ }^{30}$, malos tratos $^{31}$ y tortura ${ }^{32}$ tanto durante el arresto como en la detención de personas, detenciones arbitrarias y violaciones del debido proceso $^{33}$, desapariciones forzadas ${ }^{34}$, violación del derecho a la reunión pacífica ${ }^{35}$, violación del derecho de a la libertad de expresión ${ }^{36}$, y persecución política contra líderes y legisladores de la oposición ${ }^{37}$.

Se desprende de esta investigación que la situación cumple con los requisitos señalados anteriormente para la existencia de responsabilidad internacional. Efectivamente existieron violaciones de normas internacionales de derechos humanos básicos y estas son atribuibles al Estado venezolano dado que han ocurrido de forma

mientras que el resto habría sido resultado de la acción de civiles armados." (ACNUDH, 2017, p. 15)

29 "Las operaciones de seguridad en zonas residenciales se han caracterizado por el uso excesivo de fuerza y la destrucción deliberada de bienes, lesionando gravemente el derecho a la vivienda y a la vida privada." (ACNUDH, 2017, p. 17)

30 "En algunos casos las fuerzas de seguridad irrumpieron en las viviendas por la fuerza, destruyeron pertenencias personales y sustrajeron dinero u objetos de valor. (...) Con frecuencia, los allanamientos domiciliarios se vieron acompañados de acciones de destrucción o daño deliberado e innecesario de los bienes comunes de los conjuntos residenciales." (ACNUDH, 2017, p. 18)

31 "En casi todos los casos de detención registrados por el ACNUDH, las fuerzas de seguridad sometieron a los detenidos, incluidos los niños, a una o más formas de tratos o penas crueles, inhumanos o degradantes, equivalentes en varios casos a actos de tortura." (ACNUDH, 2017, p. 19)

${ }^{32}$ El informe detalla una serie de prácticas constatadas y corroboradas por el ACNUDH, entre las cuales se destacan las fuertes palizas en todo el cuerpo de las víctimas, quemaduras con cigarrillos, gases lacrimógenos y otros químicos usados en espacios confinados o directamente sobre las vías respiratorias, y el uso de descargas eléctricas. (ACNUDH, 2017, pp. 19-20)

33 "Entre las violaciones al debido proceso documentadas por el ACNUDH se incluyen la falta de órdenes de arresto, la detención en régimen de incomunicación, la falta de acceso a un abogado y el incumplimiento del principio de presunción de inocencia." (ACNUDH, 2017, pp. 21-22)

34 "EI ACNUDH registró varios casos de desapariciones forzadas, una forma particularmente agravada de detención arbitraria que viola las normas sustantivas y procesales en materia de derechos humanos" (ACNUDH, 2017, p. 23).

35 "Desde abril de 2017, las autoridades venezolanas han violado sistemáticamente el derecho de reunión pacífica, principalmente mediante la represión de las protestas, la criminalización de las personas que ejercen ese derecho y la imposición de restricciones indebidas a su cumplimiento" (ACNUDH, 2017, p. 26).

${ }^{36} \mathrm{El}$ informe recoge tres formas claras de violación de este derecho: (1) los ataques directos a periodistas durante las manifestaciones, mediante agresiones físicas, detenciones arbitrarias 0 destrucción de su equipo de trabajo, (2) campañas de desprestigio contra periodistas desde las más altas autoridades de gobierno, y (3) el cierre de medios de comunicación, que durante el período comprendido por el informe ya habían ascendido a 24 estaciones de radio y 4 canales de televisión que transmitían imágenes de las protestas (ACNUDH, 2017, pp. 27-30).

37 "(...) los miembros de la Asamblea Nacional sufrieron 90 ataques físicos y 44 actos de intimidación entre enero y junio de 2017. (...) El 7 de abril y el 8 de mayo, respectivamente, se inhabilitó al Gobernador de Miranda y excandidato a la presidencia, Henrique Capriles, y al Gobernador de Amazonas, Liborio Guarulla, para ejercer cargos públicos por 15 años" (ACNUDH, 2017, p. 30). 
sistemática, en muchos casos bajo las órdenes directas, planificadas y controladas por el gobierno, y en tantos otros bajo la mera, aunque no menos grave, aquiescencia del Poder Ejecutivo.

\section{2. Informe del ACNUDH de 2018}

Casi un año más tarde que el primero el Alto Comisionado publicó un segundo informe (ACNUDH, 2018). El documento aborda más en profundidad lo investigado en 2017 pero amplía su alcance para considerar violaciones ocurridas desde el año 2014 hasta la fecha de su publicación. Nuevamente, el gobierno venezolano no autorizó a la misión oficial del Alto Comisionado a ingresar al país para poder investigar, por lo que tuvo que mantenerse la misma metodología que en el anterior informe.

Además de las violaciones de derechos humanos que se señalaban en la investigación publicada en 2017, el Alto Comisionado incorporó a este informe otras violaciones que pudieron ser contrastadas y comprobadas. En este sentido, el informe de 2018 aseveró la existencia de violaciones a los derechos a la verdad y la justicia de los familiares de las personas muertas durante las protestas ${ }^{38}$, muertes en el contexto de operaciones de seguridad no relacionadas con las protestas ${ }^{39}$ y ejecuciones extrajudiciales ${ }^{40}$.

Asimismo, la investigación aborda otras violaciones de derechos humanos a más largo aliento y de mayor alcance. Este es el caso de las violaciones al derecho al más alto

\footnotetext{
38 "Las familias de las personas que murieron durante las protestas se vieron confrontadas por una serie de obstáculos recurrentes que les han impedido ejercer su derecho a la verdad, la justicia y la reparación. (...) En su informe de 2017, el ACNUDH determinó que los agentes de seguridad habían sido presuntos responsables de la muerte de 46 manifestantes. Al 31 de julio de 2017, el Ministerio Público había emitido por lo menos 54 órdenes de detención contra los agentes de seguridad presuntamente implicados en 17 de esas muertes. Sin embargo, más de un año después del comienzo de la ola de protestas, sólo se ha iniciado la etapa formal de juicio en el caso un [sólo] policía municipal"(ACNUDH, 2018, p. 9).

39 "El uso excesivo de la fuerza por parte de los cuerpos de seguridad de Venezuela en el contexto de las manifestaciones (como se expone en el informe del ACNUDH de 2017) es un aspecto de un problema más amplio, que guarda relación con el uso excesivo de la fuerza en operaciones de seguridad y que afecta al país por lo menos desde 2012" (ACNUDH, 2018, p. 15).

40 "Una organización de la sociedad civil han [sic] registrado al menos 5846 presuntas ejecuciones extrajudiciales entre 2012 y 2016 (...) [L]a anterior Fiscal General de Venezuela [Luisa Ortega Díaz] declaró que se habían llevado a cabo 1777 presuntas ejecuciones extrajudiciales en 2015, 4667 en 2016, y 1848 entre enero y junio de 2017" (ACNUDH, 2018, p. 16).
} 
nivel posible de salud ${ }^{41}$, sobre las cuales se detalla la mala administración e implementación de las políticas públicas al respecto, la dependencia en la importación de medicamentos y equipos sanitarios y la degradación de la ya limitada capacidad productiva local para elaborarlos, los abrumadores guarismos de profesionales de la salud emigrados -el $50 \%$ de los médicos y el $37 \%$ de los enfermeros han migrado a otros países de la región-, la erosión de las instalaciones hospitalarias públicas y la grave escasez de suministros sanitarios. Todos estos factores coadyuvaron al colapso de la infraestructura sanitaria y del sistema de salud.

Finalmente, el informe da cuenta de las violaciones al derecho a una alimentación adecuada $^{42}$. El Estado debe proteger este derecho, como corolario del Pacto Internacional de Derechos Económicos, Sociales y Culturales, garantizando la disponibilidad de alimentos en cantidad y calidad suficientes para satisfacer las necesidades alimentarias de las personas, así como su accesibilidad económica y física (Comité de Derechos Económicos, Sociales y Culturales, 1999, párr. 6, 8, 9, 11 13). Es en este sentido que el informe plasma la responsabilidad del gobierno venezolano y las políticas que activamente ha estado persiguiendo en la última década. Según el Alto Comisionado, la crisis económica que ha redundado en una crisis alimentaria:

Fue causada por una combinación de políticas económicas y sociales (...) como el control por el Estado del precio de los alimentos y de los tipos de cambio de moneda extranjera, la mala administración de tierras de cultivo confiscadas, el monopolio estatal de los suministros agropecuarios, la militarización de la distribución de alimentos y la puesta en práctica de programas sociales sin objetivos nutricionales claros (ACNUDH, 2018, p. 51).

Más allá de estos ostensibles fracasos en políticas públicas se podría argumentar que, frente una grave crisis económica y social, una recesión severa o cualquier situación por fuera del control del Estado que le imposibilite el cumplimiento de dicha obligación,

\footnotetext{
41 "Todos los médicos, académicos, otros profesionales de la salud, y defensores de los derechos humanos que fueron entrevistados por el ACNUDH, coincidieron en señalar que el país sufre de una dramática crisis sanitaria y de un completo colapso del sistema de atención sanitaria, que ha resultado en violaciones masivas al derecho a la salud" (ACNUDH, 2018, p. 43).

42 "La profunda recesión económica, la hiperinflación y la pérdida de poder adquisitivo, junto con el desmantelamiento del sistema de producción nacional de alimentos y la dependencia con respecto a las importaciones de alimentos, han creado un círculo vicioso que ha afectado el derecho a la alimentación de la mayoría de los venezolanos" (ACNUDH, 2018, p. 50).
} 
éste estaría inhibido de tal responsabilidad. Este argumento es correcto (Comité de Derechos Económicos, Sociales y Culturales, 1999, párr. 17), sin embargo, el Estado está obligado a demostrar que ha hecho todos los esfuerzos posibles con todos los recursos con que dispone para garantizar acceso mínimo y prioritario de las personas que no pueden obtener alimentos por sus propios medios. Según el ACNUDH en su informe de 2018, el gobierno venezolano no ha podido demostrar esto ${ }^{43}$.

Paralelamente, el Estado no puede rechazar asistencia humanitaria sin encontrarse, por ese acto, incumpliendo con el Pacto Internacional de Derechos Económicos, Sociales y Culturales. "[I]mpedir el acceso a ayuda alimentaria de carácter humanitario en los conflictos internos o en otras situaciones de emergencia" son actos que constituyen violaciones al derecho a la alimentación adecuada (Comité de Derechos Económicos, Sociales y Culturales, 1999, párr. 19). Lamentablemente, las autoridades del gobierno venezolano han rechazado en numerosas ocasiones la asistencia humanitaria brindada por la comunidad internacional (Radio Televisión Martí, 2017; Gilbert, 2018; Hu y Britton, 2019), particularmente aquella proveniente de rivales ideológicos, como los Estados Unidos o el Grupo de Lima. No obstante, esta práctica no supone un ejercicio soberano de la independencia nacional dado que el contexto de una emergencia alimentaria no habilita a los funcionarios del Estado a arrogarse la facultad de mantener a sus conciudadanos en una situación de desprotección de un derecho humano absolutamente básico, como lo es la alimentación. El rechazo de la ayuda alimentaria constituye, en el contexto del caso concreto, una grave contravención del Pacto Internacional de Derechos Económicos, Sociales y Culturales, nuevamente, atribuible al Estado venezolano.

\section{3. Informe de ACNUDH de 2019}

El 4 de julio de 2019, la Alta Comisionada de las Naciones Unidas para los Derechos Humanos Michelle Bachelet presentó su informe sobre la situación de Venezuela ante

\footnotetext{
${ }^{43} \mathrm{El}$ informe resalta tres programas destinados al suministro alimentario de la población con el objetivo de garantizar su alimentación. Estos fueron: (1) el plan "Gran Misión de Abastecimiento Soberano", destinado a desarrollar a los pequeños agricultores y promover la agricultura urbana, fracasó con la escasez de suministros agrícolas, semillas, fertilizantes y agua; (2) el Estado de excepción y emergencia económica, destinado a combatir la "guerra económica", militarizó la distribución y comercialización de alimentos; y (3) el programa CLAP, destinado a distribuir alimentos casa a casa mediante una caja de suministros básicos y con un precio controlado por el Estado que, según el informe, no satisface las necesidades nutricionales de los venezolanos, no tiene un mecanismo de rendiciones de cuentas y ha sido utilizado como una herramienta de propaganda política y control social. (ACNUDH, 2018, p. 56)
} 
el Consejo de Derechos Humanos (ACNUDH, 2019a). El documento abarca el período comprendido entre enero de 2018 y mayo de 2019, sin embargo, realiza algunos análisis de mayor alcance cronológico como, por ejemplo, afirmar que en la última década, especialmente desde 2016, el gobierno venezolano ha desplegado una estrategia para "neutralizar, reprimir y criminalizar" (ACNUDH, 2019b, párr. 30) a la oposición política y a quienes critican al Gobierno.

Una de las novedades de este informe con respecto a los anteriores, es que el ACNUDH tuvo autorización, por vez primera, del gobierno venezolano para ingresar en el país y conducir las investigaciones pertinentes. Quedan en el mundo de lo especulativo las razones por las cuales sucedió este cambio. La creciente presión de la comunidad internacional, la delicada situación política del régimen, el deterioro de la situación económica y social de Venezuela o la vecindad cultural o la aparente cercanía ideológica de la Alta Comisionada Michelle Bachelet, pudieron haber sido factores que propiciaron esta apertura. Lo más plausible es que todos estos elementos hayan influido en mayor o menor medida en la decisión del gobierno.

Otra de las consideraciones que aparece en el reporte refiere a las medidas coercitivas unilaterales ejercidas por varios Estados y una organización regional, que el gobierno venezolano utiliza argumentando que estas son el origen de la crisis económica (ACNUDH, 2019b, párr. 26). El informe detalla la naturaleza de estas sanciones señalando que sólo aquellas efectuadas por Estados Unidos configuran sanciones sectoriales amplias con impacto directo en la economía venezolana y, por lo tanto, en los derechos humanos de su población ${ }^{44}$. No obstante, se manifiesta que la crisis económica y el colapso del sistema productivo venezolano, tanto petrolero como alimentario, había comenzado mucho antes que la aplicación de las sanciones. El reporte no ignora ni desconoce el impacto de dichas sanciones haciendo especial hincapié en que la mayoría de las divisas internacionales provienen de la exportación del sector petrolero, que depende sustancialmente del mercado norteamericano (ACNUDH, 2019b, párr. 27).

En definitiva, si bien las sanciones de Estados Unidos tienen un claro impacto en las exportaciones de crudo del país y por lo tanto serias repercusiones en cadena, no se

${ }^{44}$ Las sanciones llevadas adelante por otros países y por la Unión Europea son acciones selectivas que afectan a individuos particulares -restringiendo su capacidad de viaje y congelando sus activos financieros en el exterior- o que suponen embargos de armas. (ACNUDH, 2019b, párr. 25) 
puede sostener que el estado precario y deteriorado de la estructura económica del país se deba a las mismas. Así es como resulta al menos curioso el ejercicio argumental desplegado por el gobierno venezolano como respuesta a este punto, el cual señaló que el génesis de la crisis económica se encontraba en el desmoronamiento del precio del crudo, ocurrido tras la manipulación de los precios por parte de Estados Unidos desde 2014 gracias a la superproducción de petróleo (ACNUDH, 2019c, párr. 37). El cómo se vincula el fraking norteamericano y la tendencia a la baja global del precio de este producto, con la incapacidad del gobierno venezolano de sostener los sistemas de producción y distribución de alimentos en perjuicio de sus derechos humanos fundamentales, por ejemplo, es una pregunta a la que aún no le hemos encontrado respuesta ${ }^{45}$.

El informe de 2019 aborda, además, las violaciones de derechos humanos que ya han sido tratados en los informes precedentes dado que estas graves contravenciones continuaron o se repitieron durante todo el período de estudio.

El reporte señala que "se han cometido graves violaciones de los derechos económicos y sociales, incluidos los derechos a la alimentación y a la salud (...) El Gobierno se negó a reconocer la magnitud de la crisis hasta hace poco y no adoptó las medidas apropiadas" (ACNUDH, 2019b, párr. 75).

La Alta Comisionada asegura también que durante la última década Venezuela "ha adoptado una serie de leyes, políticas y prácticas que han restringido el espacio democrático, debilitado las instituciones públicas y menoscabado la independencia del poder judicial" (ACNUDH, 2019b, párr. 76). Estas medidas fueron tomadas bajo la supuesta finalidad de preservar el orden público y el estado de derecho protegiendo a la nación de las amenazas internas y externas. Sin embargo, estas transformaciones "han aumentado la militarización de las instituciones del Estado y el empleo de la población civil en tareas de inteligencia y defensa".

Una línea aparece en las conclusiones que no había surgido en anteriores informes. Se asegura que:

Las autoridades han atacado especialmente a determinadas personas y grupos, entre ellos a miembros de la oposición política (...) Esta represión selectiva se

${ }^{45}$ Cabe señalar que el ACHNUDH no abre juicio sobre la legalidad o ilegalidad de las sanciones americanas, lo que se verá más adelante, en el punto 6.c de este trabajo. 
manifiesta en una multitud de violaciones de derechos humanos, que pueden constituir persecución por motivos políticos. Estas violaciones requieren más investigación para determinar la pertinente responsabilidad del Estado y la responsabilidad penal individual (ACNUDH, 2019b, párr. 77).

Es la primera vez, en los tres informes del ACNUDH, que el término "responsabilidad del Estado" figura. Lamentablemente, el término solamente se vincula con los delitos de persecución política y violación de los derechos civiles y políticos de los venezolanos. Ciertamente debería estudiarse la responsabilidad del Estado por todas las violaciones de derechos humanos que se describen en estos informes cada vez más categóricos y amplios.

Como corolario de esta redacción pormenorizada sobre los detalles contenidos en los informes de los Altos Comisionados, a los ojos del derecho internacional las autoridades venezolanas, por acción y omisión, han violentado sistemáticamente los derechos humanos de la población en diferentes dimensiones y en diverso grado. Desde los derechos a la alimentación y a la mejor salud posible de la gran mayoría de sus conciudadanos hasta los derechos a la libre expresión, integridad física, debido proceso y la vida de cientos o miles de manifestantes y opositores.

\section{4. Informe del Consejo de Derechos Humanos del 2020}

El 27 de setiembre de 2019, tras haber considerado los informes previos del ACNUDH y las denuncias allí plasmadas, el Consejo de Derechos Humanos de Naciones Unidas decidió establecer una misión internacional independiente con el objetivo de investigar específicamente las ejecuciones extrajudiciales, las desapariciones forzadas, las detenciones arbitrarias y las torturas y otros tratos crueles, inhumanos o degradantes cometidos desde 2014 (CDH, 2019, párr. 24). Un año más tarde, el 15 de setiembre de 2020, los resultados de dicha investigación fueron plasmados en dos documentos: un informe de la misión (un resumen de 21 páginas con la información más relevante) $(\mathrm{CDH}, 2020 \mathrm{a})$ y las conclusiones detalladas de la misión (un extensivo documento de más de 440 páginas donde se abordan los casos específicos con precisión) (CDH, 2020b).

La investigación concluyó la existencia de motivos razonables para creer que en Venezuela se cometieron violaciones de derechos humanos y crímenes de lesa humanidad desde 2014 en tres dimensiones diferentes: (1) represión política selectiva 
(violaciones contra opositores del gobierno); (2) represión en el contexto de seguridad y control social (atropellos ocurridos durante operaciones policiales); y (3) violaciones en el contexto de las protestas (crímenes perpetrados en contra de manifestantes).

El informe señala que las:

Violaciones de los derechos humanos y los delitos investigados por la Misión y descritos en el presente informe dan lugar a la responsabilidad del Estado y a la responsabilidad penal individual, ya sea en virtud del derecho penal nacional o internacional, o de ambos. (CDH, 2020b, párr. 152).

Otro de los pasajes que revisten igual gravedad es aquel que menciona que:

La mayoría de las violaciones y crímenes documentados en el presente informe se cometieron en el marco de un ataque generalizado y sistemático dirigido contra la población civil, con conocimiento del ataque, de conformidad con (...) políticas estatales o en apoyo a las mismas (CDH, 2020b, párr. 2086).

Estas conclusiones son lapidarias en cuanto a la responsabilidad del Estado venezolano, así como de aquellos individuos que cometieron los abusos y crímenes que se vienen perpetrando desde 2014 contra la población civil venezolana. Si bien el informe aclara que la misión no trató de determinar las modalidades de participación en estas violaciones, sí pudo demostrar que "las autoridades estatales -tanto a nivel presidencial como ministerial- tenían y ejercían su poder y supervisión sobre las fuerzas y organismos de seguridad civiles y militares identificados (...) como autores de violaciones y delitos documentados" (CDH, 2020b, párr. 2096).

La misión internacional independiente del Consejo de Derechos Humanos no solamente reafirma el contenido de los anteriores informes, sino que comprueba y determina la existencia de violaciones graves que suponen la responsabilidad del Estado, así como la responsabilidad penal individual de aquellos que los llevaron a cabo.

\section{5. La Corte Penal Internacional}

La gravedad de las violaciones de derechos humanos señaladas en estas páginas movilizó a una serie de actores internacionales para activar uno de los mecanismos punitivos existentes. 
La primera denuncia fue la elevada por la ex fiscal general de Venezuela, Luisa Ortega, en noviembre de 2017. Según sus propias declaraciones contaba con elementos probatorios de las violaciones de derechos humanos cometidas durante las protestas de ese convulsionado año.

El 8 de febrero de 2018, la Fiscal de la Corte Penal Internacional Fatou Bensouda decidía abrir un examen preliminar sobre la situación en Venezuela centrando el análisis sobre los alegados crímenes de lesa humanidad cometidos al menos desde abril de 2017 (CPI, 2018a). En su comunicado la fiscal destacó que "un examen preliminar no es una investigación, sino un proceso por el cual se examina la información disponible para determinar (...) si existe fundamento razonable para proceder a una investigación" (CPI, 2018a, párr. 5). Para esto la fiscalía "tomará en cuenta toda comunicación y punto de vista que se le presente" (CPI, 2018a, párr. 7).

En este sentido, debemos hacer mención de un extensivo informe de la Secretaría General de la OEA conjuntamente con un panel de expertos independientes donde se:

Estima que existe fundamento suficiente, que satisface los criterios de prueba contemplados en el Artículo 53 del Estatuto de Roma, para considerar que los actos a los que ha sido sometida la población civil de Venezuela, que se remontan por lo menos al 12 de febrero de 2014, constituyen crímenes de lesa humanidad, (...) incluyendo los crímenes de asesinato, encarcelación, tortura, violación y otras formas de violencia sexual, persecución y desapariciones forzadas (OEA, 2018e, p. 463).

Este informe, publicado en mayo de 2018 y elevado a la Fiscalía de la Corte Penal Internacional, pone de manifiesto lo que hemos afirmado anteriormente con respecto a la responsabilidad que las autoridades venezolanas cargan con respecto al atropello de los derechos humanos de sus compatriotas. Resulta indudable que este documento es un aporte al examen preliminar de la CPI con el objetivo de que la decisión final sea iniciar una investigación formal y un juicio a los alegados responsables.

Si bien la fiscal ya había abierto el procedimiento en febrero de 2018 , en setiembre de ese año le fue remitida la situación por parte de seis Estados ${ }^{46}$, con arreglo al artículo 14 del Estatuto de Roma (CPI, 2018b). En palabras de la propia fiscal, esta remisión "no [conlleva] automáticamente a la apertura de una investigación" (CPI, 2018a, párr.

\footnotetext{
${ }^{46}$ Argentina, Canadá, Colombia, Chile, Paraguay y Perú.
} 
5), en el sentido de que queda a criterio del fiscal si existe mérito suficiente para el inicio del proceso. En dicha remisión los seis Estados, todos del continente americano, hacen sustantivas referencias al informe de la Secretaría General de la OEA citado en el párrafo anterior. Los Estados solicitaban a la fiscal que investigara las supuestas violaciones cometidas en Venezuela desde febrero de 2014, un período sensiblemente más dilatado que lo que se sostenía hasta el momento. Desde iniciado el examen preliminar el caso se ha mantenido incambiado. Si bien han ocurrido algunos movimientos menores -modificaciones en las cámaras que tratan el caso- la investigación, ni mucho menos el juicio formal de los responsables, ha comenzado.

Curiosamente, el caso investigado en contra del gobierno venezolano no es el único presente en estos momentos en la CPI. Existe otro examen preliminar-denominado Venezuela II- referido por la propia Venezuela en contra de Estados Unidos, dado que se han cometido crímenes de lesa humanidad "como resultado de la aplicación de medidas coercitivas ilegales adoptadas unilateralmente por el gobierno de los Estados Unidos de América contra Venezuela, al menos desde al año 2014" (CPI, 2020, párrafo 2). Este es el mismo argumento sostenido por las autoridades venezolanas para eximirse de la responsabilidad de las masivas violaciones de derechos económicos y sociales ${ }^{47}$.

\section{INFLUENCIA Y PRESIÓN INTERNACIONAL EN VENEZUELA}

El objetivo de este apartado es analizar la variedad de factores externos que se han introducido en la ecuación venezolana, desde presiones internacionales directas e indirectas, sanciones de diversos actores, hasta la presencia de efectivos militares extranjeros y operaciones por parte de organizaciones criminales.

\section{1. Presencia armada extranjera}

\footnotetext{
${ }^{47}$ La CPI no aporta más detalles sobre la denuncia realizada por el gobierno venezolano. No obstante, según declaraciones de sus autoridades, la misma tendría un fundamento "bien sustentado" dado que las sanciones tomadas por Estados Unidos "se parecen a la persecución del pueblo judío". Cabe decir que, tomando en cuenta la información pública sobre la denuncia y las disposiciones del Estatuto de Roma, los alegados crímenes de lesa humanidad provocados por las sanciones económicas solo encontrarían un lugar bajo el artículo 7, literal k, cuando refiere a otros actos inhumanos que causen intencionalmente graves sufrimientos a una población civil. Esta sería la única taxonomía jurídica en la que una sanción económica pudiera escuadrarse como un crimen de lesa humanidad. (DW Español, 2020a)
} 
La colaboración y coordinación entre las fuerzas armadas de diversos países no constituye una violación del derecho internacional. Los tratados entre Estados sobre esta materia son usuales y legítimos (Prieto Sanjuán, 2012, pp. 27-64). Por tanto, ¿existiría alguna contravención del derecho internacional al probarse la existencia de fuerzas militares extranjeras en Venezuela? Nosotros creemos que esta pregunta merece al menos la reflexión y el debate en el caso concreto.

La presencia de militares cubanos en suelo venezolano ha sido documentada en numerosas ocasiones. Investigaciones periodísticas (Naím, 2014; Semple, 2019; Blanco, 2019; Borges, 2019; Radio Televisión Martí 2019), de organizaciones no gubernamentales (Blanco et al., 2019; Ocando, 2019), autoridades militares disidentes (Delgado, 2015) así lo señalan, al igual que el propio presidente de los Estados Unidos, Donald Trump (El País Uruguay, 2019; Oppmann, 2019). Sin embargo, como hemos dicho, esta presencia per se no supone un hecho ilícito dado que el gobierno venezolano consiente en la presencia de estos efectivos.

Es por ello que el asunto debe analizarse desde la perspectiva del alcance de esta colaboración. Ninguna justificación podría elaborarse sobre la sola base de la presencia de tropas o la existencia de programas de entrenamiento. A pesar de esto, de comprobarse el control efectivo de unidades militares o de inteligencia por parte de autoridades cubanas, como una investigación periodística afirma (Berwick, 2019), el resultado puede ser muy diferente.

El control efectivo de tropas, de agentes de seguridad o de inteligencia, aunque sean extranjeros, abre la puerta de la responsabilidad internacional del Estado. Si estos agentes (cubanos) del Estado venezolano cometen crímenes de lesa humanidad o violentan los derechos fundamentales de personas, entonces el Estado que ejerce el control efectivo incurriría paralelamente en el mismo grado de responsabilidad que aquel que aporta las fuerzas. Según la Comisión de Derecho Internacional, esto sucedería si existiera "dirección y control ejercida sobre la comisión del hecho internacionalmente ilícito" ${ }^{48}$.

E incluso en el caso de alegarse que las autoridades y oficiales cubanos no ejercen control directo de las fuerzas y que se limitan al entrenamiento de los soldados y agentes venezolanos, aun así, la Comisión establece la responsabilidad derivada, en

\footnotetext{
${ }^{48}$ Artículo 17 en conjunción con el artículo 47 (AGNU, 2001, p. 5).
} 
el caso de existir ilícitos internacionales, dado que la ayuda y asistencia en la consumación de tales actos es igualmente penalizada ${ }^{49}$. Un Estado que facilita la perpetración de hechos ilícitos por parte de otro, incurre en responsabilidad internacional por la extensión de los daños causados por dicha asistencia (CDI, 2001, art. 16, párr. 1).

La misma tesis es aplicable a la asistencia proveniente de otros países -como Rusia (DW Español, 2019; González, 2020), China (Blasco, 2017) o Irán (DW Español, 2020b)-, especialmente si toma la forma de envíos de armamento $^{50}$. En este sentido la Comisión de Derecho Internacional no dejó dudas al respecto cuando expresó que "un Estado puede incurrir en responsabilidad si (...) proporciona ayuda material a un Estado que utilice esa ayuda para cometer violaciones de los derechos humanos. A ese respecto, la Asamblea General ha instado en diversas ocasiones a los Estados Miembros a abstenerse de suministrar armas y otra asistencia militar a países que se considera que cometen graves violaciones de los derechos humanos" (CDI, 2001, art. 16, párr. 9).

\section{2. Presión norteamericana}

Estados Unidos ha cobrado un papel preponderante como principal exponente de la presión internacional contra el gobierno de Nicolás Maduro. Washington ha realizado progresivos avances, tanto en su retórica como con medidas concretas, para intentar presionar a las autoridades de Venezuela y resolver la situación de crisis política, económica y humanitaria.

En este punto abordaremos los ofrecimientos de amnistía a militares y hasta al propio Nicolás Maduro, las acusaciones por parte de EEUU a altos cargos del gobierno venezolano sobre narcotráfico y el reciente despliegue de fuerzas armadas en el Mar Caribe. Este apartado no tratará las sanciones económicas unilaterales que se verán en el punto siguiente.

En 2019 Estados Unidos ofreció "amnistía" a altos mandos militares venezolanos (Martín, 2019) así como al propio Nicolás Maduro (Infobae, 2019c). Poca claridad

\footnotetext{
${ }^{49}$ Artículo 16 en conjunción con el artículo 47 (AGNU, 2001).

${ }^{50} \mathrm{Si}$ bien desde el inicio de la crisis económica venezolana las compras de armamento se han visto disminuidas formidablemente, la base de datos del Instituto de Investigación para la Paz Internacional de Estocolmo (SIRPI, por sus siglas en inglés) evidencia que, en la última década, el $76 \%$ de las armas venezolanas han sido provistas por dos exportadores: Rusia (en un $60 \%$ ) y China (en un $16 \%$ ).
} 
existe respecto a qué tipo de amnistía se estaba ofreciendo. De las manifestaciones recogidas por la prensa se puede inferir que se trataba de inmunidad a alguna forma de persecución penal por parte de Estados Unidos. Es ostensible que para que exista esto los potenciales amnistiados debieron haber cometido algún delito perseguible en la jurisdicción norteamericana. Como se explica más adelante, el Departamento de Justicia de este país realizó finalmente dichas acusaciones en marzo de 2020. No obstante, la inmunidad a estos delitos no les liberaría de la responsabilidad criminal por otros cometidos en jurisdicción venezolana. Asimismo, es evidente que Estados Unidos no tiene competencia para ofrecer o garantizar la inmunidad de los oficiales venezolanos ante potenciales futuros procesos judiciales en Venezuela o ejercidos por otros tribunales, como la Corte Penal Internacional. Sin perjuicio de esto, debe señalarse que el ofrecimiento de amnistía contraviene además la jurisprudencia de la Corte Interamericana de los Derechos Humanos, quien sostiene, de forma fundada, su ilegalidad en el marco del derecho internacional (Gelman vs. Uruguay, 2011, párr. 195). Una amnistía viola, en la mayoría de los casos, los derechos de las víctimas de crímenes de lesa humanidad, dado que gracias a ese instrumento no pueden obtener verdad ni justicia por los crímenes del amnistiado.

Resulta ineludible destacar lo poco convencional de las acusaciones realizadas el 26 de marzo de 2020. El fiscal general de los Estados Unidos, William Barr, formalizó ese día a Nicolás Maduro y otros catorce altos funcionarios de su gobierno por los delitos de narcoterrorismo, corrupción, tráfico de drogas y otros cargos criminales (Departamento de Justicia de EEUU, 2020). Según Barr, Maduro y sus acompañantes constituyeron una extensiva organización criminal con el objetivo de "inundar" los Estados Unidos con cocaína desde hace unos 20 años. Se afirma que el Cártel de Los Soles tiene por principales jefes a Nicolás Maduro y Diosdado Cabello (segundo del gobierno y actual presidente de la ANC) el cual, en connivencia con las Fuerzas Armadas Revolucionarias de Colombia (FARC), han establecido centros de refinamiento y producción de estupefacientes en Venezuela así como coordinado operaciones de transporte marítimo y aéreo a través de Centro América y el Caribe. El Departamento de Estado estima que aproximadamente 250 toneladas de cocaína son traficadas en estas operaciones hacia los Estados Unidos. 
$\mathrm{Si}$ bien las acusaciones resultan impresionantes y que no es el gobierno norteamericano el único en hacerlas (Blanco et al., 2019), habrá que esperar a la investigación y las pruebas que así lo acrediten para dar veracidad a estos dichos.

Veamos la situación desde la perspectiva del derecho internacional.

El argumento de Washington es que Nicolás Maduro y su cúpula de oficiales son un régimen ilegítimo a los que no reconocen como la autoridad de Venezuela, siendo Juan Guaidó y sus representantes aquellos que legalmente ejercen la función gubernamental.

Como hemos señalado previamente, la legitimidad democrática de un gobierno no es, de principio, un requisito indispensable para su reconocimiento y por ende a contrario sensu para proceder a un no reconocimiento automático por ese motivo (Lauterpacht, 2013, pp. 98-104). El principal requisito para tener en cuenta a la hora del reconocimiento suele ser la efectividad, es decir que ejerza su poder sobre la mayoría de la población de su Estado y que este sea aceptado por aquellos ${ }^{51}$. Si bien no está prohibido y es discrecional de cada gobierno proceder al reconocimiento de otro gobierno, para el caso concreto, es justamente la efectividad del gobierno de Juan Guaidó que resulta particularmente debatible por lo que no puede descartarse livianamente la autoridad de Nicolás Maduro y su gabinete que son los que ejercen efectivamente el poder. El reconocimiento no es constitutivo, es declarativo y no se puede declarar lo que no es real y pretender que eso tiene implicancias jurídicas absolutas en todos los planos.

Esta línea de pensamiento otorgaría a Nicolás Maduro, a los ojos del derecho internacional, todas las prerrogativas que revisten los jefes de Estado y de gobierno del mundo. ¿Esto invalidaría las acusaciones o las definiría como ilegítimas? Ciertamente no, nada en el derecho inhabilita a los Estados a acusar penalmente a las personas que ejerzan altos cargos en el gobierno de otros Estados sin importar lo inusual de esta situación. No obstante, las inmunidades inherentes a su cargo se mantendrían en pie, por lo que ningún Estado, mientras la persona haga ejercicio de esas funciones, podría efectivamente perseguirlo, detenerlo o arrestarlo.

Tras las acusaciones realizadas por el gobierno norteamericano, se desplegaron fuerzas navales en el Mar Caribe con el objetivo declarado de realizar operaciones

\footnotetext{
${ }^{51}$ Ver ejemplos, supra nota 6.
} 
anti-drogas para bloquear las alegadas rutas de narcotráfico provenientes de Venezuela (Spetalnick y Stewart, 2020; Goodman, 2020). En la conferencia de prensa donde Donald Trump oficializó las medidas, el Secretario de Defensa Mike Esper declaró que Nicolás Maduro y sus altos funcionarios "dependen de las ganancias derivadas de las ventas de narcóticos para mantener su control opresivo del poder" (Spetalnick y Stewart, 2020, párrafo 9). La flota desplegada por Estados Unidos en aguas cercanas a las venezolanas con el expreso objetivo de amedrentar y presionar a sus autoridades a dimitir puede constituir una amenaza al uso de la fuerza (Sadurska, 1988, pp. 239-268), así como una violación directa al principio de no intervención. Incluso al entenderse que las operaciones tienen el sólo propósito de luchar contra el narcotráfico, el resultado de las maniobras es el mismo: el patrullaje en aguas cercanas y el constante apremio de la fuerza de las armas.

La situación de amenaza latente se mantiene. Máxime si se toma en cuenta la retórica de Donald Trump, quien afirmó que una intervención militar en Venezuela era una opción posible para dar respuesta a la crisis política (Ellsworth, 2019). Las próximas elecciones 2020 en Estados Unidos podrán quizás producir una modificación en relación con esta política respecto de Venezuela.

\section{3. Medidas coercitivas unilaterales}

Como se ha señalado en este trabajo, varios Estados impulsaron "sanciones"52 en contra del gobierno venezolano. En la mayoría de los casos -Canadá, Colombia, México, Panamá y Suiza- se tratan de medidas selectivas orientadas a altos funcionarios venezolanos aplicando congelación de fondos, proscripción de contratación de nacionales con aquellos y la prohibición de entrada al país. Si bien los otros dos grandes actores en materia de sanciones, EE.UU. y la Unión Europea también las ejercieron dirigidas a altos funcionarios, nos enfocaremos en aquellas medidas que sobrepasan a individuos particulares, concretamente las de naturaleza comercial.

La Unión Europea, desde 2017, ha establecido un embargo de venta de armas sobre Venezuela, lo que supone que ninguno de sus Estados parte puede comerciar armas

${ }^{52}$ Como se verá más adelante, el término "sanciones" es técnicamente aplicable únicamente a aquellas medidas tomadas en el marco de una acción coercitiva colectiva e institucional. La definición correcta para estas "sanciones" por parte de Estados sería la de "medidas coercitivas unilaterales", o en su caso, "contramedidas" o "retorsiones". 
con Caracas (Semple y Krauss, 2017). Desde entonces ha prorrogado la medida año tras año. La cuestión sobre la legalidad de este tipo de embargos para el derecho internacional, no ofrece dudas. Los Estados cuentan con la capacidad legal de limitar y restringir aquellos mercados a los que venden armamento (Acuerdo General sobre Aranceles Aduaneros y Comercio, 1994, art. XXI.b.ii; AGNU, 2013, párr. 3) e incluso, en ciertos casos, tienen la obligación de hacerlo (Tratado sobre el Comercio de Armas, 2013, art. 6.3).

Existen diferencias entre este caso y algunos embargos de otra naturaleza que se han aplicado a Venezuela, que pueden ser considerados cuestionables o ilegales: se trata de las medidas coercitivas unilaterales comerciales.

La Asamblea General de Naciones Unidas, a través de su Consejo de Derechos Humanos, ha venido emitiendo de forma constante, resoluciones en contra de las sanciones comerciales o embargos que constituyen medidas coercitivas unilaterales (AGNU, 2014).

Debe señalarse que, pese a la condena a estas medidas por ese órgano, no puede concluirse que esta manifestación suponga la emergencia de un derecho consuetudinario en la materia. La doctrina parece reafirmar que este tema se encuentra en un área gris del derecho internacional, la práctica de los Estados es diversa y no se alinea frente a una sola posición, y la jurisprudencia no es mayoritaria como para afirmar lo contrario (Hofer, 2017, párr. 7-9, 30-38).

Sin perjuicio de esto, en el caso de estudio, la suspensión unilateral de las relaciones comerciales de Estados Unidos con Venezuela no parece configurar una retorsión (es decir, una medida inamistosa pero legal) sino una medida que se encuentra dentro de las medidas coercitivas unilaterales que no encuentran justificación jurídica. La misma no se encuentra evidentemente adoptada en el marco de las excepciones previstas en el artículo XXI del GATT-OMC, que habilitan la suspensión de las obligaciones que se tienen en materia comercial dada una "emergencia en las relaciones internacionales" (1994, art. XXI.b.iii; OMC, 1995, pp. 600-610) sino que persiguen una finalidad sancionatoria que supera ese marco jurídico.

Ante esto, la argumentación de los EE.UU. para justificar este embargo comercial, es que el mismo constituye una contramedida, es decir una medida que en circunstancias ordinarias violaría una obligación internacional, pero que un Estado lesionado puede 
tomar válidamente contra un Estado responsable de un hecho ilícito, para que el mismo cese (CDI, 2001, p. 137). En el caso concreto, Venezuela habría cometido un hecho internacionalmente ilícito al cometer violaciones de derechos humanos contra su propia población, siendo el embargo comercial una contramedida posible.

La CDI, en su proyecto de artículos sobre Responsabilidad de los Estados por Hechos Internacionalmente llícitos, en su artículo 54, leído en conjunción con el 48, habilita la posibilidad de que un Estado, como miembro de la comunidad internacional, pueda ejercer contramedidas contra otro que haya violado normas imperativas de derecho internacional, sujeto a muchas restricciones, entre ellas que se impongan "en interés del beneficiario". Para luego concluir que "como muestra este análisis, el estado actual del derecho internacional sobre las contramedidas adoptadas en interés general o colectivo es incierto" (CDI, 2001, p. 149), por lo cual la habilitación genérica inicial no se confirma realmente en la conclusión.

Por ende, debe concluirse que existe un estado incierto de habilitación de las medidas coercitivas unilaterales y, para el caso, siguiendo incluso la interpretación más afín a la argumentación de EE.UU., que dichas medidas solo se podrían instrumentar si fueran adoptadas "en interés del beneficiario" que en este caso sería el pueblo venezolano, restando en este caso probar si las contramedidas comerciales efectivamente cumplen con esa premisa o bien todo lo contrario.

\section{4. Sanciones en el marco del TIAR}

Mediante la aplicación del Tratado Interamericano de Asistencia Recíproca (TIAR), los Estados del continente impusieron sanciones a veintinueve individuos que forman parte o son cercanos al gobierno de Nicolás Maduro. La resolución del 3 de diciembre de 2019 estableció sanciones institucionales colectivas similares, en naturaleza y alcance, a aquellas dictadas por la Unión Europea (OEA, 2019c). No obstante, la importancia de este análisis particular radica en el instrumento jurídico en el cual se fundamentan dichas sanciones y la interpretación que los Estados miembros hicieron de sus disposiciones.

Según la resolución mencionada, "la crisis política, económica y social en (...) Venezuela representa una amenaza para el mantenimiento de la paz y la seguridad del Continente" (OEA, 2019c, p.1), por lo que se habilitaría la aplicación de medidas en virtud del artículo 6 del TIAR. 
Esto contraviene el espíritu original del tratado que es, en palabras de su preámbulo, el "asegurar la paz por todos los medios posibles, proveer ayuda recíproca efectiva para hacer frente a los ataques armados contra cualquier Estado Americano y conjurar las amenazas de agresión contra cualquiera de ellos" (1947). EI TIAR es un tratado de asistencia mutua entre los Estados del continente americano frente a ataques armados extra o intrarregionales.

Coincidimos, en este sentido, con la posición adoptada por Uruguay al considerar que el tratado no fue diseñado para afrontar colectivamente conflictos políticos internos 0 amenazas internas a la seguridad de un Estado en particular (OEA, 2019d).

Por otro lado, la redacción del artículo 6 del TIAR habilita la imposición de sanciones en caso de "una agresión que no sea ataque armado" o "un conflicto (...) intracontinental, (...) que pueda poner en peligro la paz de América". Si bien estas palabras incluyen situaciones que no sean ataques armados, ampliando sustancialmente su margen de aplicación, se puede fácilmente inferir que refiere a una situación de amenaza a la paz continental, es decir, una circunstancia de extrema tensión entre Estados que pueda resultar en un conflicto bélico. Para que se configure una "agresión", en el contexto del artículo 6, debe tratarse de un acto unilateral no armado que genere un daño a un Estado del continente. La crisis venezolana, a pesar del enorme sufrimiento humano que ha producido, no configura esta hipótesis.

Este argumento refuerza la posición que fue planteada en el párrafo anterior: la situación de Venezuela es una crisis multidimensional interna, que si bien produce efectos que impactan en la región (esencialmente la crisis migratoria), no puede decirse que califique como amenaza a la paz regional. La adopción de estas sanciones en este marco, resultan una politización sin respaldo jurídico de un instrumento de legítima defensa colectiva como el TIAR, -que, por cierto, nunca tuvo mucha importancia práctica como tratado-, lo cual no quita lo improcedente de lo actuado.

\section{SITUACIÓN ACTUAL Y PERSPECTIVAS}

En junio de 2020, el Tribunal Supremo de Justicia de Venezuela designó los nuevos miembros del Consejo Nacional Electoral, la máxima autoridad en materia de comicios del país. Dicha acción se encontró con el fuerte rechazo del parlamento dado que se trata de una competencia exclusiva del poder legislativo en virtud del texto 
constitucional. Se entendió en ese momento como un avance del gobierno de Nicolás Maduro para avasallar los próximos procesos electorales que tendrían lugar en Venezuela en diciembre de 2020 (BBC Mundo, 2020).

Un mes después, el 1 de julio de 2020, el Consejo Nacional Electoral anunció la convocatoria a nuevas elecciones parlamentarias destinadas a renovar la Asamblea Nacional. La oposición rechazó en bloque este proceso, indicando que no participará ni reconocerá lo que califica como "fraude electoral". Según la oposición venezolana, hoy mayoría absoluta de la Asamblea Nacional, los comicios que se realizarán el 6 de diciembre carecen de las garantías mínimas, tal como lo hicieron las elecciones de 2018 (Reuters, 2020).

Resulta evidente que el último reducto opositor dentro de Venezuela es la Asamblea Nacional, sustento de la legitimidad alegada del gobierno de Guaidó. La renovación del parlamento, mediante comicios opacos y a todas luces controlados por el poder ejecutivo, podrían otorgar al régimen una apariencia de legitimidad institucional.

Encontrándonos al finalizar este trabajo a mediados de setiembre de 2020, el camino trazado hacia adelante parece encaminarse a agregar más de lo mismo, en una situación que ya ha acumulado un sinfín de situaciones irregulares por ambos bandos. No obstante, parece claro que no encontrará una salida de la actual crisis política y económica hasta que no exista consenso, transparencia y garantías democráticas en sus procesos electorales.

\section{VIII.CONCLUSIONES}

- Las situaciones abordadas en los puntos 2 y 3 de este trabajo dan cuenta de situaciones que permiten determinar la inexistencia de una separación real entre poderes públicos y una manipulación por parte del oficialismo para obtener la victoria en las elecciones que lo confirmaron en el poder, las que no fueron libres. Por esto podemos concluir que el gobierno de Nicolás Maduro se configura como un régimen de facto al no contar fehacientemente con estos dos elementos esenciales de una democracia, incluidos en los instrumentos interamericanos sobre el tema.

- La legalidad de la proclamación de Juan Guaidó y su gobierno no tiene una fundamentación jurídica sólida, ni desde un punto de vista constitucional 
interno, ni desde un punto de vista internacional. El autoproclamado presidente carece de eficacia y control territorial y su condición de jefe de gobierno venezolano no responde a la realidad de los hechos, ni se desprende de una correcta interpretación del derecho, sino a una realidad política degradada que precisa de un líder opositor "legítimo", frente a un régimen de facto.

- En tal sentido, su reconocimiento como jefe del gobierno de Venezuela es un acto político declarativo que no encuentra una fundamentación adecuada en el derecho internacional, generalmente opuesto a teorías legitimistas (siempre opinables) y más afecto a considerar la autoridad efectiva del gobernante. Debe quedar claro que la condición de presidente de facto de Maduro (y su eventual no reconocimiento) no son fundamento automático para un reconocimiento de Guaidó que debe ser justificado por sí mismo.

- Las instancias internacionales (existentes o creadas ad hoc) para la solución del conflicto venezolano no han dado los frutos esperados:

- El Grupo de Lima sostiene una retórica y un accionar rayano en el intervencionismo colectivo, claramente sesgado ideológicamente.

- El Consejo de Seguridad de Naciones Unidas se encuentra paralizado por los intereses políticos de sus miembros permanentes.

- La OEA ha mostrado ser ineficaz en lograr resultados concretos pese a sus denuncias contra el gobierno de Maduro. No logró aplicar la Carta Democrática contra Venezuela. Sólo ha logrado condenas no efectivas, el retiro voluntario de Venezuela de la Organización, tener un conflicto mal resuelto sobre la titularidad de la representación de ese país en sus órganos y promover una mala utilización del TIAR.

- El Grupo Internacional de Contacto aparece como un camino que, al menos en lo formal, transita el camino del diálogo y el acercamiento entre las partes sin inmiscuirse en consideraciones que puedan configurar una injerencia inaceptable, pese a que exige elecciones generales como una precondición negociadora.

- La evidencia sobre las violaciones de los derechos humanos cometidos por el Gobierno de Maduro resulta comprobada por diferentes fuentes. La persecución política de opositores, la restricción de la libre expresión, las detenciones arbitrarias sin debido proceso, las torturas y malos tratos 
cometidos, han sido documentados. En este sentido existe responsabilidad del Estado por estos hechos, así como responsabilidad de los autores materiales y sus superiores jerárquicos, es decir las principales figuras del actual gobierno.

- La investigación llevada adelante por la fiscal general de la Corte Penal Internacional por los supuestos crímenes de lesa humanidad cometidos por el gobierno de Nicolás Maduro dará una nueva pauta sobre el alcance individual de las responsabilidades en este campo.

- La presión directa de terceros Estados u organizaciones mediante amenazas del uso de la fuerza o aplicación de medidas coercitivas unilaterales de cualquier tipo, resultan reprobables. Su justificación por las violaciones en materia de DD.HH. cometidas por el gobierno de Venezuela no constituye un argumento que tenga respaldo unánime, constituyendo una violación al principio de no intervención.

- Las eventuales sanciones deben tener un carácter multilateral. La comunidad internacional (ONU y OEA para este caso concreto) diseñaron un sistema en donde los Estados están sometidos al cumplimiento de los principios de derecho internacional público $\mathrm{y}$, en caso de no hacerlo, a respetar las decisiones de los órganos multilaterales previstos a tales efectos donde se procesan las violaciones y las sanciones que correspondan. Si por el fracaso de estas organizaciones la nueva regla sancionatoria pasara a ser la aplicación de medidas coercitivas unilaterales, el sistema establecido se regirá por relaciones de poder y perderá toda razón de ser.

- Ante un fracaso del multilateralismo institucional, es mucho más productivo y acorde a derecho promover mecanismos internacionales alternativos de diálogo que se manejen con flexibilidad y equilibrio, respetando el principio de autodeterminación que indica que en última instancia la solución debe ser resuelta por los venezolanos antes que seguir adelante con las presiones unilaterales.

- Los argumentos de una sola vía no responden a la realidad de la crisis venezolana. Un análisis desapasionado, necesariamente interpretativo pero lo más objetivo posible, nos muestra que ambas partes (y terceros Estados) han violado normas de derecho internacional en Venezuela en el periodo 
considerado. Priorizar las violaciones de los diferentes actores en más o menos graves es parte de un proceso diferente que supondría contraponer diferentes normas de jus cogens entre sí, además de considerar otras violaciones de menor gravedad, que no es el propósito de este trabajo.

- La ruptura del orden democrático en Venezuela y la violación fragrante y sistemática de los derechos humanos de su población civil son condenables, pero no suponen una habilitación automática para la intervención unilateral internacional. De igual forma, la fuerte presión política, la injerencia exterior en los asuntos domésticos venezolanos, la amenaza del uso de la fuerza y los embargos económicos, no conforman una justificación para los actos perpetrados por el gobierno de Nicolás Maduro contrarios al derecho internacional.

\section{BiBLIOGRAFÍA}

ACNUDH (2014a, 6 de marzo). Venezuela/Manifestaciones: Expertos de la ONU piden aclaración sobre supuestas detenciones arbitrarias y uso de violencia [comunicado de prensa].https://www.ohchr.org/SP/NewsEvents/Pages/DisplayNews.aspx?NewsID=143 18\&amp;LangID $=S$

ACNUDH (2014b, 20 de octubre), Venezuela/DDHH: Alto Comisionado de la ONU pide liberar manifestantes y políticos detenidos arbitrariamente [comunicado de prensa].https://www.ohchr.org/SP/NewsEvents/Pages/DisplayNews.aspx?NewsID=151 87\&amp;LanglD=S

ACNUDH (2017). Violaciones y abusos de los derechos humanos en el contexto de las protestas en la República Bolivariana de Venezuela del 1 de abril al 31 de julio de 2017.

ACNUDH

https://www.ohchr.org/Documents/Countries/VE/HCReportVenezuela 1April31July2017 SP.pdf

ACNUDH (2018). Violaciones de los Derechos Humanos en la República Bolivariana de Venezuela: una espiral descendente que no parece tener fin. ACNUDH https://www.ohchr.org/Documents/Countries/VE/VenezuelaReport2018 SP.pdf

ACNUDH (2019a, 4 de julio). Informe de la Oficina de las Naciones Unidas para los Derechos Humanos sobre Venezuela insta a adoptar de inmediato medidas para detener y remediar graves violaciones de derechos [comunicado de prensa]. https://www.ohchr.org/SP/NewsEvents/Pages/DisplayNews.aspx?NewsID=24788\&am $\underline{\mathrm{p} ; \text { Lang } I \mathrm{D}=\mathrm{S}}$

ACNUDH (2019b, 4 de julio). Informe de la Alta Comisionada de las Naciones Unidas para los Derechos Humanos sobre la situación de los derechos humanos en la República Bolivariana de Venezuela (A/HRC/41/18) [comunicado de prensa]. 
https://www.ohchr.org/SP/NewsEvents/Pages/DisplayNews.aspx?NewsID=24788\&am $\mathrm{p} ;$ LanglD $=\mathrm{S}$

ACNUDH (2019c, 4 de julio). Informe de la Alta Comisionada de las Naciones Unidas para los Derechos Humanos sobre la situación de los derechos humanos en la República Bolivariana de Venezuela: Comentarios del Estado (A/HRC/41/18/Add.1) [comunicado de prensa]. https://www.ohchr.org/SP/NewsEvents/Pages/DisplayNews.aspx?NewsID=24788\&am $\underline{\mathrm{p} ; \text { LanglD }=\mathrm{S}}$

Acuerdo General sobre Aranceles Aduaneros y Comercio. (1994). https://www.wto.org/spanish/docs s/legal s/legal s.htm\#goods

AGNU (2001). Responsabilidad del Estado por hechos internacionalmente ilícitos (A/RES/56/83). https://undocs.org/pdf?symbol=es/A/RES/56/83

AGNU. (2013). Repercusiones de las transferencias de armas en los derechos humanos durante los conflictos armados (A/HRC/RES/24/35). https://undocs.org/A/HRC/RES/24/35.

AGNU. (2014). Derechos humanos y medidas coercitivas unilaterales (A/HRC/RES/27/21). https://undocs.org/en/A/HRC/RES/27/21

Armas, M. y Pons, C. (2019, 24 de enero). Guaidó se autoproclama presidente interino de Venezuela con apoyo de EEUU y otros países. Reuters. https://es.reuters.com/article/topNews/idESKCN1PI0JW-OESTP

Banchón, M. (2019. 09 de mayo). Grupo Internacional de Contacto: 'El único camino para resolver la crisis en Venezuela'. DW Español. https://p.dw.com/p/3IFqp

Barcelona Traction, Light and Power Company, Limited (Bélgica c. España), Sentencia en segunda fase de las Objeciones Preliminares (Corte Internacional de Justicia 1970). https://legal.un.org/icjsummaries/documents/spanish/st leg serf1.pdf

BBC Mundo. (2017a, 31 de marzo). Fiscal general de Venezuela, Luisa Ortega Díaz, dice que sentencias del Tribunal Supremo sobre Asamblea Nacional violan el orden constitucional. https://www.bbc.com/mundo/noticias-america-latina-39459905

BBC Mundo. (2017b, 31 de julio). Venezuela elige la Asamblea Nacional Constituyente en controvertidas elecciones con el 41,53\% de participación popular, según el Consejo Nacional Electoral. https://www.bbc.com/mundo/noticias-america-latina-40772815

BBC Mundo. (2017c, 4 de agosto). Se instala la polémica Asamblea Nacional Constituyente de Venezuela presidida por la excanciller Delcy Rodríguez. https://www.bbc.com/mundo/noticias-america-latina-40806539

BBC Mundo. (2017d, 18 de agosto). La Asamblea Constituyente de Venezuela asume funciones legislativas del Parlamento controlado por la oposición. https://www.bbc.com/mundo/noticias-america-latina-40981405

BBC Mundo. (2017e, 1 de abril). Venezuela: el Consejo de Defensa pide al Tribunal Supremo de Justicia que revise sus decisiones sobre la Asamblea Nacional. https://www.bbc.com/mundo/noticias-america-latina-39402013 
BBC Mundo. (2018, 23 de enero). La Asamblea Constituyente de Venezuela aprueba celebrar elecciones presidenciales antes de mayo y Maduro formaliza su candidatura. https://www.bbc.com/mundo/noticias-america-latina-42796683

BBC Mundo. (2020, 13 de junio). La polémica designación del Tribunal Supremo de Venezuela de un nuevo Consejo Electoral: ¿qué significa para el conflicto político del país?. https://www.bbc.com/mundo/noticias-america-latina-53031926

Berwick, A. (2019, 22 de agosto). Represión importada: Cómo Cuba enseñó a Venezuela a sofocar el disenso militar. Reuters. https://www.reuters.com/investigates/special-report/venezuela-cuba-military-es/

Blanco, J. (2019, 20 de febrero) Pruebas de la presencia militar cubana en las Fuerzas Armadas venezolanas. Panama Post. https://es.panampost.com/josefinablanco/2019/02/20/cuba-venezuela-militar/

Blanco, J., Cataya, R., Domínguez, L. y Ocando, C. (2019) Cubazuela: crónica de una intervención cubana. Fundation for Human Rights in Cuba. https://www.fhrcuba.org/wp-content/uploads/2019/04/CUBAZUELA-INTERVENCIONSPANISH-APRIL-9.pdf

Blasco, E. (2017, 06 de abril). China sustituye a Rusia como principal proveedor de armas a Venezuela. ABC. https://www.abc.es/internacional/abci-china-sustituye-rusiacomo-principal-proveedor-armas-venezuela-

201704052203 noticia.html?ref=https:\%2F\%2Fwww.google.com\%2F

Borges, J. (2019, 10 de abril). Cuba Has Hijacked Venezuela. The New York Times. https://www.nytimes.com/2019/04/10/opinion/venezuela-julioborges.html?searchResultPosition=5

Brotóns R. A., Pérez L., Riquelme R., Diez J. y Orihuela E. (2007). Derecho Internacional. Tirant Lo Blanch.

Carta de la Organización de Estados Americanos. (1948). http://www.oas.org/es/sla/ddi/tratados multilaterales interamericanos A41 carta OEA.asp

CDI. (2001). Proyecto de artículos sobre la Responsabilidad del Estado por Hechos Internacionalmente llícitos, con comentarios.

CDH. (2019). Situación de los derechos humanos en la República Bolivariana de Venezuela (A/HRC/RES/42/25).

$\mathrm{CDH}$. (2020a). Informe de la misión internacional independiente de determinación de los hechos sobre la República Bolivariana de Venezuela (A/HRC/45/33).

$\mathrm{CDH}$. (2020b). Conclusiones detalladas de la Misión internacional independiente de determinación de los hechos sobre la República Bolivariana de Venezuela (A/HRC/45/CRP.11).

Colina G. y Vanolli H. (2017). Informe: Elecciones Asamblea Nacional Constituyente 2017. Observatorio Global de Comunicación y Democracia. 
Comité de Derechos Económicos, Sociales y Culturales. (1999). El derecho a una alimentación adecuada (art. 11) (Observación General №12, E/C.12/1999/5).

Convención Americana sobre Derechos Humanos (1969).

CNN Español. (2015). Tribunal Supremo de Justicia de Venezuela suspende proclamación de 4 diputados. https://cnnespanol.cnn.com/2015/12/30/tribunalsupremo-de-justicia-de-venezuela-suspende-proclamacion-de-4-diputados/

CNN Español. (2017). Los países que no reconocerán la Constituyente de Venezuela y los que sí. https://cnnespanol.cnn.com/2017/07/31/los-paises-que-no-reconoceran-laconstituyente-de-venezuela-y-los-que-si/

CPI (2018a). Declaración de la Fiscal de la Corte Penal Internacional, Sra. Fatou Bensouda, sobre la apertura de exámenes preliminares en Filipinas y Venezuela. https://www.icc-cpi.int/Pages/item.aspx?name=180208-otp-stat\&amp;In=Spanish

CPI (2018b). Declaración de la Fiscal de la Corte Penal Internacional, Sra. Fatou Bensouda, sobre la remisión por parte de un grupo de seis Estados Partes en relación con la situación en Venezuela. https://www.icc-cpi.int/Pages/item.aspx?name=180927otp-stat-venezuela\&amp;In=Spanish

CPI (2020). Venezuela II. Examen preliminar. https://www.icc-cpi.int/venezuelall

Crawford, J. (2012). Brownlie's Principles of International Law (8 ${ }^{\mathrm{a}}$ ed.). Oxford Unviersity Press.

CSNU. (2019a). United States of America: draft resolution (S/2019/186).

CSNU. (2019b). Russian Federation: draft resolution (S/2019/190).

Declaración de Lima. (2017). http://es.presidencia.gov.co/noticia/170808-Declaracionde-Lima-sobre-la-situacion-de-Venezuela

Decreto N²830. (2017). Gaceta Oficial de la República Bolivariana de Venezuela ( $\left.\mathrm{N}^{\circ} 6295\right)$.

Delgado, A. M. (2015). General Rivero: Cuba tiene a 20.000 hombres listos para el combate en Venezuela. El Nuevo Herald. https://www.elnuevoherald.com/noticias/mundo/america-latina/venezuelaes/article8593799.html

Departamento de Justicia de EEUU. (2020). Nicolás Maduro Moros and 14 Current and Former Venezuelan Officials Charged with Narco-Terrorism, Corruption, Drug Trafficking and Other Criminal Charges. Recuperado de https://www.justice.gov/opa/pr/nicol-s-maduro-moros-and-14-current-and-formervenezuelan-officials-charged-narco-terrorism

DW Español. (2016). Venezuela: Tribunal declara 'en desacato' al Parlamento. https://p.dw.com/p/1Hbdv

DW Español. (2017). Fiscal de Venezuela pide anular convocatoria a Constituyente. Recuperado de https://p.dw.com/p/2eMN2 
DW Español. (2019). Más tropas rusas llegarán a Venezuela, anuncia régimen chavista. https://p.dw.com/p/3GG1H

DW Español. (2020a). Venezuela denuncia a Estados Unidos ante la Corte Penal Internacional. https://p.dw.com/p/3Xk9l

DW Español. (2020b). Irán advierte a EEUU para que permita la entrega de petróleo a Venezuela. https://p.dw.com/p/3cN31

El Español. (2017). Protestas en las calles de Venezuela por la decisión del Supremo. https://www.elespanol.com/mundo/america/20170331/205009498 3.html

Ellsworth, B. (2019). Trump says U.S. military intervention in Venezuela 'an option'; Rusia objects. Reuters. https://www.reuters.com/article/us-venezuela-politics/trumpsays-u-s-military-intervention-in-venezuela-an-option-russia-objects-idUSKCN1PSODK

Ellsworth, B. y Sequera, V. (2019). Norway says Venezuela opposition and government talks to continue. Reuters. https://www.reuters.com/article/us-venezuelapolitics/norway-says-venezuela-opposition-and-government-talks-to-continue-

idUSKCN1U61XX

El País Uruguay. (2019). Trump dijo que Maduro es un 'títere' de Cuba y advirtió a militares que lo defienden. https://www.elpais.com.uy/mundo/trump-dijo-maduro-titerecuba-advirtio-militares-defienden.html

Europa Press. (2016). Cronología de un año de crisis institucional en Venezuela. https://www.europapress.es/internacional/noticia-cronologia-ano-crisis-institucionalvenezuela-20161206081638.html

Europa Press. (2019). La Asamblea Nacional tacha a Maduro de 'usurpador' y asume sus poderes como presidente de Venezuela. https://www.europapress.es/internacional/noticia-asamblea-nacional-tacha-madurousurpador-asume-poderes-presidente-venezuela-20190115193300.html

García Marco, D. G. (2018). Elecciones en Venezuela: qué dice la alta abstención sobre las presidenciales en las que fue reelecto Nicolás Maduro. BBC Mundo. Recuperado de https://www.bbc.com/mundo/noticias-america-latina-44192914

Gelman vs. Uruguay, Sentencia sobre Fondo y Reparaciones (Corte Interamericana de Derechos Humanos 2011).

Gilbert, A. (2018). Venezuela rechaza la oferta de ayuda humanitaria del Grupo de Lima. El Periódico. https://www.elperiodico.com/es/internacional/20180905/venezuelarechaza-llamado-latinoamericano-a-aceptar-ayuda-humanitaria-7019706

González, D. (2020). Rusia anuncia apoyo militar a Venezuela. France24. https://www.france24.com/es/20200208-rusia-anuncia-apoyo-militar-a-venezuela

Goodman, J. (2020). Trump: US to deploy anti-drug Navy ships near Venezuela. Associated Press. https://apnews.com/d4c51884ba3ac6a4311b6f548434f958 
Grupo de Lima. (2018a). Declaración del Grupo de Lima. http://www.itamaraty.gov.br/es/notas-a-la-prensa/18271-declaracion-del-grupo-de-lima$\underline{2018}$

Grupo de Lima. (2018b). Declaración del Grupo de Lima. http://www.itamaraty.gov.br/es/notas-a-la-prensa/19095-declaracion-del-grupo-de-lima

Grupo de Lima. (2019a) Declaración del Grupo de Lima. http://www.itamaraty.gov.br/es/notas-a-la-prensa/20030-declaracion-del-grupo-de-lima4-de-febrero-de-2019

Grupo de Lima. (2019b) Declaración del Grupo de Lima en apoyo al proceso de transición democrática y reconstrucción de Venezuela. http://www.itamaraty.gov.br/es/notas-a-la-prensa/20132-declaracion-del-grupo-de-limaem-apoyo-al-processo-de-transicion-democratica-y-la-reconstruccion-de-venezuelabogota-25-de-febrero-de-2019

Hernández, A. (2017). Cómo Venezuela pasó de 4 meses de choques y protestas diarias a una aparente calma. BBC Mundo. https://www.bbc.com/mundo/noticiasamerica-latina- 41577319

Hofer, A. (2017). The Developed/Developing Divide on Unliateral Coercive Measures: Legitimate enforcement or illegitimate intervention?. CJIL.

Hu, C. y Britton, B. (2019). El Gobierno de Maduro rechaza la ayuda humanitaria y anuncia envío de alimentos a Colombia. CNN Español. https://cnnespanol.cnn.com/2019/02/19/el-gobierno-de-maduro-rechaza-la-ayudahumanitaria-y-anuncia-envio-de-alimentos-a-colombia/

Infobae. (2017). La abstención en la elección de la Asamblea Constituyente de Maduro fue superior al 87\%. https://www.infobae.com/america/venezuela/2017/07/30/laoposicion-estimo-que-solo-un-9-del-padron-electoral-voto-para-la-asambleaconstituyente-de-nicolas-maduro/

Infobae. (2019a). Las 4 etapas del Mecanismo de Montevideo para solucionar la crisis en Venezuela. https://www.infobae.com/america/venezuela/2019/02/06/las-4-etapasdel-mecanismo-de-montevideo-para-solucionar-la-crisis-en-venezuela/

Infobae. (2019b). El Grupo de Contacto comenzó una reunión marcada por la preocupación por la escalada de la crisis venezolana. https://www.infobae.com/america/venezuela/2019/05/07/el-grupo-de-contactocomenzo-una-reunion-marcada-por-la-preocupacion-por-la-escalada-de-la-crisisvenezolanal

Infobae. (2019c). Estados Unidos ofrece amnistía a Nicolás Maduro: 'Queremos que tenga una salida digna y que se vaya'. https://www.infobae.com/america/the-new-yorktimes/2019/08/28/estados-unidos-ofrece-amnistia-a-nicolas-maduro-queremos-quetenga-una-salida-digna-y-que-se-vayal

Infobae. (2020a). El Grupo de Contacto Internacional concluyó que en Venezuela "no se cumplen las condiciones para un proceso electoral transparente". https://www.infobae.com/america/venezuela/2020/09/17/el-grupo-de-contacto- 
internacional-concluyo-que-en-venezuela-no-se-cumplen-las-condiciones-para-unproceso-electoral-transparente/

Infobae. (2020b). Nuevas protestas por la falta de gasolina y el racionamiento en distintas ciudades de Venezuela. https://www.infobae.com/america/venezuela/2020/06/03/nuevas-protestas-por-la-faltade-gasolina-y-el-racionamiento-en-distintas-ciudades-de-venezuela/

Jiménez de Aréchaga, E., Arbuet, H. y Pucceiro, R. (2005). Derecho Internacional Público. Tomo I. Fundación de Cultura Universitaria.

Laise, L. D. y Manzo, G. (2019). Constitucionalismo abusivo y tutela judicial efectiva: El comienzo del quiebre institucional venezolano. Universitas.

Landau, D. (2013). Abusive Constitutionalism. U. C. Davis Law Review, 47(1).

Lauterpacht, H. (2013). Recognition in International Law. Cambridge University Press.

Ley de Amnistía y Reconciliación Nacional (2016) Asamblea Nacional de la República Bolivariana de Venezuela.

Martín, S. (2019). Rubio ofrece amnistía a militares venezolanos que cooperen. Panam Post. https://es.panampost.com/sabrina-martin/2019/02/12/militares-maduro-eeuu/

MERCOSUR. (2017a). Declaración de los Estados Partes del Mercosur sobre la República Bolivariana de Venezuela.

MERCOSUR. (2017b). Decisión sobre la suspensión de la República Bolivariana de Venezuela en el Mercosur en aplicación del Protocolo de Ushuaia sobre compromiso democrático en el Mercosur.

MERCOSUR. (2019). Declaración presidencial sobre el fortalecimiento de la democracia en el Mercosur.

Ministerio de Relaciones Exteriores del Brasil (2018). Situación de Venezuela. http://www.itamaraty.gov.br/es/notas-a-la-prensa/18551-situacion-en-venezuela-2018

Naím, M. (2014). ¿Cómo conquistó Cuba a Venezuela?. El País. https://elpais.com/internacional/2014/04/19/actualidad/1397936093 048585.html

Ocando, C. (2019). Exclusiva: Los secretos de la invasión militar cubana en Venezuela. Primer informe. https://primerinforme.com/index.php/2019/04/13/secretosde-la-invasion-militar-cubana-en-venezuela/

OEA. (2017a). Resolución sobre los sucesos recientes en Venezuela (CP/RES. 1078).

OEA. (2017b). Mensaje del Secretario General sobre Venezuela (D-025/17).

OEA. (2017c). Secretaría General de la OEA respalda decisión de Mercosur sobre Venezuela (C-062/17).

OEA (2018a). Resolución sobre los Últimos Acontecimientos en Venezuela (CP/RES. 1095).

OEA. (2018b). Resolución sobre la Situación de Venezuela (AG/RES. 2929). 
OEA. (2018c). Mensaje del Secretario General de la OEA sobre elecciones en Venezuela.

https://www.oas.org/es/centro noticias/comunicado prensa.asp?sCodigo=D-019/18

OEA. (2018d). Venezuela: Secretaría General de la OEA llama a desconocer solicitudes de extradición de la dictadura. https://www.oas.org/es/centro noticias/comunicado prensa.asp?sCodigo=C-052/18

OEA. (2018e). Informe de la Secretaría General de la Organización de los Estados Americanos y del panel de expertos internacionales independientes sobre la posible comisión de crímenes de lesa humanidad en Venezuela. http://www.oas.org/documents/spa/press/Informe-Panel-Independiente-VenezuelaES.pdf

OEA. (2019a). Resolución sobre la situación en Venezuela (CP/RES. 1117).

OEA. (2019b). Resolución sobre la situación en Venezuela (CP/RES. 1124).

OEA (2019c). La crisis de la República Bolivariana de Venezuela y sus impactos desestabilizadores para el hemisferio (RC.30/RES. 2/19).

OEA. (2019d). Convocatoria a la reunión del órgano de consulta del Tratado Interamericano de Asistencia Recíproca (TIAR) (CP/RES. 1137 (2245/19)).

OMC. (1995). Guide to GATT Law and Practice. Vol. I. OMC

Oppmann, P. (2019). Donald Trump amenaza a Cuba con un bloqueo completo si sigue apoyando a Venezuela. CNN Español. https://cnnespanol.cnn.com/video/venezuela-injerencia-cuba-tropas-militares-estadosunidos-sanciones-pkg-patrick-oppmann/

Pacto Internacional de Derechos Económicos, Sociales y Culturales. (1966)

Pacto Internacional de Derechos Civiles y Políticos. (1966)

Primer Protocolo Facultativo del Pacto Internacional de Derechos Civiles y Políticos. (1966)

Segundo Protocolo Facultativo del Pacto Internacional de Derechos Civiles y Políticos. (1989)

Pastori, A. (2020). La obligación democrática en el derecho internacional público: primera parte (Estudio N³/20). CURI.

Prieto Sanjuán, R. A. (2012). Acuerdos de cooperación y bases militares en territorio extranjero: ¿un "acto de agresión”...? Anuario Mexicano de Derecho Internacional.

Protocolo de Ushuaia sobre Compromiso Democrático en el MERCOSUR, la República de Bolivia y la República de Chile. (1998)

Radio Televisión Martí. (2017). Ministro de Salud de Venezuela rechaza ayuda humanitaria. https://www.radiotelevisionmarti.com/a/ministro-salud-venezuela-rechazaayuda-humanitaria/157499.html 
Reuters. (2018). Coalición opositora de Venezuela dice que no participará en elección presidencial 'ilegítima'. https://ta.reuters.com/articulo/politica-venezuelapresidenciales-idLTAKCN1G52FA-OUSLT

Reuters. (2019a). EEUU condena la 'usurpación del poder' de Maduro en Venezuela. https://es.reuters.com/article/topNews/idESKCN1P50H1-OESTP

Reuters. (2019b). Venezuela's opposition says Norway-mediated dialogue with Maduro 'is finished'. https://www.reuters.com/article/us-venezuela-politics/venezuelasopposition-says-norway-mediated-dialogue-with-maduro-is-finished-idUSKBN1W100J

Reuters. (2020). Oposición venezolana dice que no participará en elecciones legislativas.

https://www.reuters.com/article/venezuela-politica-eleccionesidLTAKBN24Y0N4

Roncagliolo, I. (2015). El principio de no intervención: consagración, evolución y problemas en el Derecho Internacional actual. 21(1). lus et Praxis.

Sadurska, R. (1988). Threats of Force. Vol. 82, №2. AJIL.

Salinas, A. y Andreu-Guzmán, F. (2017). El Tribunal Supremo de Justicia de Venezuela: un instrumento del poder ejecutivo. Comisión Internacional de Juristas,.

Sánchez, D. M. (2019). Convocatoria y elección de una constituyente: colisión con el Poder Constituido. 1(1). Estado de Derecho Rechtsstaat.

Semple, K. (2019). With Spies and Other Operatives, a Nation Looms Over Venezuela's Crisis: Cuba. The New York Times. https://www.nytimes.com/2019/01/26/world/americas/venezuela-cubaoil.html?searchResultPosition $=7$

Semple K. y Krauss C. (2017). La Unión Europea aprueba embargo de armas contra Venezuela. The New York Times. https://www.nytimes.com/es/2017/11/14/espanol/venezuela-embargo-armas-unioneuropea.html

Sentencia $N^{\circ}$ 01. (Sala Electoral del Tribunal Supremo de Justicia de Venezuela 2016)

Sentencia №260. (Sala Electoral del Tribunal Supremo de Justicia de Venezuela 2015)

Sentencia $N^{\circ} 156$. (Sala Constitucional del Tribunal Supremo de Justicia de Venezuela 2017)

Sentencia $N^{\circ} 157$. (Sala Constitucional del Tribunal Supremo de Justicia de Venezuela 2017)

Sentencia N ${ }^{\circ} 158$. (Sala Constitucional del Tribunal Supremo de Justicia de Venezuela 2017)

Shaw, M. (2008). International Law (6 $6^{\mathrm{a}}$ ed.). Cambridge Univerity Press.

Spetalnick, M. y Stewart, P. (2020). Trump doubles U.S. military assets in Caribbean, bolstering drug fight after Maduro indictment. Reuters. 
https://www.reuters.com/article/us-usa-venezuela-navy/trump-doubles-us-militaryassets-in-caribbean-bolstering-drug-fight-after-maduro-indictment-idUSKBN21 J6VH

TeleSur. (2017). Hermann Escarrá: El Poder Judicial es el custodio del Estado constitucional de derecho en Venezuela. https://www.telesurtv.net/opinion/HermannEscarra-El-Poder-Judicial-es-el-custodio-del-Estado-constitucional-de-derecho20170331-0003.html

TeleSur. (2019). Qué establece el Mecanismo de Montevideo y por qué se abandonó. https://www.telesurtv.net/news/mecanismo-montevideo-venezuela-uruguay-mexico20190407-0004.html

Tratado Interamericano de Asistencia Recíproca. (1947).

Tratado sobre el Comercio de Armas. (2013).

Unión Europea. (2018a). Declaración de la Alta Representante en nombre de la UE sobre la situación en Venezuela. https://www.consilium.europa.eu/es/press/pressreleases/2018/04/19/declaration-by-the-high-representative-on-behalf-of-the-eu-on-thesituation-in-venezuela/

Unión Europea. (2018b). Declaración de la Alta Representante, en nombre de la UE, sobre las elecciones presidenciales $y$ regionales en Venezuela. https://www.consilium.europa.eu/es/press/press-releases/2018/05/22/declaration-bythe-high-representative-on-behalf-of-the-eu-on-the-presidential-and-regional-electionsin-venezuela/

Univisión. (2017). Presión internacional obliga a Maduro a pedirle al Supremo que revise el fallo que es calificado como golpe de Estado. https://www.univision.com/noticias/crisis-en-venezuela/maduro-pide-al-tribunalsupremo-venezolano-revisar-los-fallos-que-arrebataron-competencias-al-legislativo

Vinogradoff, L. (2018). Venezuela adelanta las elecciones presidenciales antes de mayo. $A B C$ Internacional. https://bit.ly/3eqYulF

Zamorano, A. (2014). Venezuela: un mes de protestas en las que todos pierden. BBC Mundo.

https://www.bbc.com/mundo/noticias/2014/03/140311 venezuela protestas mes az

PAstori Filliol, Alejandro: Profesor (Catedrático) de Derecho Internacional Público de la Facultad de Derecho de la Universidad de la República (Montevideo, Uruguay), alejandropastori@adinet.com.uy.

Ramos, Sebastián: Aspirante a Profesor Adscripto de Derecho Internacional Público de la Facultad de Derecho de la Universidad de la República (Montevideo, Uruguay), sebastianramoszeballos@gmail.com. 